\title{
Near-Infrared Spectroscopy-Its Versatility in Analytical Chemistry
}

\author{
Yukihiro OzAKI \\ Department of Chemistry, School of Science and Technology, Kwansei Gakuin University, Sanda, \\ Hyogo 669-1337, Japan
}

\begin{abstract}
The purpose of this review article is to outline recent progress in near-infrared (NIR) spectroscopy. Some particular emphasis is put on the delineation of its versatility in analytical chemistry. NIR spectroscopy is versatile in many aspects. For example, it is electronic spectroscopy as well as vibrational spectroscopy. It is also all-round in applications from basic to practical applications. NIR spectroscopy can be applied to various kinds of materials, bulk materials, thin or thick polymers, tablets, human bodies, and so on. It is particularly powerful in non-invasive, non-destructive, and in situ analysis. In this review, the principles and advantages of NIR spectroscopy are described first, and then its applications to various fields, including polymer science, on-line monitoring, inorganic material research, medical diagnosis, and NIR imaging are introduced.
\end{abstract}

(Received January 31, 2012; Accepted February 28, 2012; Published June 10, 2012)

1 Introduction

2 Principles and Advantages of NIR Spectroscopy 546

$2 \cdot 1$ Brief history of NIR spectroscopy

$2 \cdot 2$ Principles of NIR spectroscopy

2.3 Advantages of NIR spectroscopy

3 Analysis of NIR Spectra

$3 \cdot 1$ Conventional spectral analysis method

3.2 Chemometrics

4 Application
4.1 Applications to polymer science and engineering

4.2 Applications to process analysis

4.3 Applications of NIR electronic spectroscopy to inorganic functional materials

4.4 Biomedical applications

4.5 Applications of NIR imaging

5 Future Prospects

6 References

\section{Introduction}

Near-infrared (NIR) spectroscopy is spectroscopy in the region of $800-2500 \mathrm{~nm}\left(12500-4000 \mathrm{~cm}^{-1}\right.$; in this review both wavelength $(\mathrm{nm})$ and wavenumber $\left(\mathrm{cm}^{-1}\right)$ are used). ${ }^{1-10}$ This

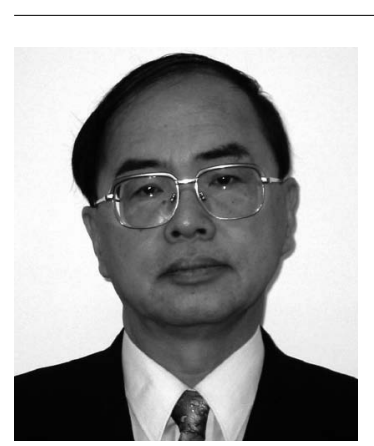

Yukihiro OzaKI received M. S. (1975) and $\mathrm{Ph}$. D. (1978) degrees in chemistry from Osaka University. Currently, he holds a position of professor in the Department of Chemistry, School of Science and Technology, Kwansei Gakuin University. He has been an Associate Editor of Applied Spectroscopy since 2009. His research program has been concerned with basic studies and applications of far ultraviolet (FUV), infrared (IR), Raman, and near-infrared (NIR) spectroscopy. He has received many awards, including the 1998 Tomas Hirschfeld Award, the 2001 EAS Award for Achievements in Near Infrared Spectroscopy, the Spectroscopical Society of Japan Award (2002), the 2005 Science and Technology Award of Japanese Government (Ministry of Education, Culture, Sports, Science and Technology), and the Japan Society for Analytical Chemistry Award (2008).

E-mail: ozaki@kwansei.ac.jp region is in-between the visible and IR regions. In general, NIR spectroscopy is concerned with the absorption, emission, reflection and diffuse-reflection of light. During the last two decades or so, NIR spectroscopy has made marked progress in its applications to basic science as well as applied science. ${ }^{1-10}$ The purpose of this review is to demonstrate "versatility" of NIR spectroscopy in analytical chemistry with emphasis on recent progress. NIR spectroscopy is versatile in several aspects. First of all, it is electronic spectroscopy as well as vibrational spectroscopy. IR, Raman, and NIR spectroscopy form the "three sisters of vibrational spectroscopy" (if we add terahertz spectroscopy, they become "four sisters"). Since NIR spectroscopy is concerned only with overtones and combination modes, it is very much unique compared with IR and Raman spectroscopy, but it is undoubtedly a member of the sisters. One should not forget that NIR spectroscopy is involved in the electronic transitions of molecules. It is well known that a number of molecules yield absorption bands due to electronic transitions in the NIR region. Electronic NIR spectroscopy also has some applications. ${ }^{11-15}$ For example, an in vivo measurement of oxyhemoglobin $\left(\mathrm{HbO}_{2}\right)$ in blood is a good example. ${ }^{13}$

The versatility of NIR spectroscopy also exists in its

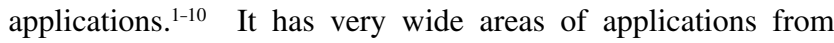
basic sciences to food and agricultural engineering, on-line 
monitoring, biomedicine, and environmental science. One can use NIR spectroscopy in a laboratory, a factory, a hospital, fields, on a road and in the atmosphere.

NIR spectrometers and instruments also include different things from IR spectrometers and instruments. ${ }^{1-10}$ In the IR region, most of the spectrometers used are FT spectrometers, while in the visible region, scanning dispersive spectrometers are usually employed. For NIR spectroscopy both FT spectrometers and dispersive spectrometers are used, and dispersive spectrometers with a CCD detector play important roles in the short-wave NIR (SWNIR) region. Portable spectrometers and hand-held spectrometers are also very popular. It seems as if the NIR region is a battle field of spectrometers.

Yet another diversity in NIR spectroscopy is that of spectral analysis. Compared with other spectroscopy, chemometrics is quite often used for NIR spectral analysis. ${ }^{1-10,16-20}$ One can say that chemometrics has been developed along with the progress of NIR spectroscopy. A variety of spectral pretreatments are employed in NIR spectroscopy, since it treats various bulk materials, which give rise to noise and baseline fluctuations.

Obviously, NIR spectroscopy has huge versatility in applications. ${ }^{1-10}$ It is applied to solids, crystals, fibers, powders, liquids, solutions, and gases. Almost all kinds of materials, from purified samples to bulk materials, can be subjected to NIR measurements. The application fields of NIR spectroscopy are described in Sect. 4.

In this review, the principles and advantages of NIR spectroscopy, including its brief history, are described first. The analysis of NIR spectra is outlined in some detail next, and after that a number of applications of NIR spectroscopy are introduced. As for the details of the principles, one should refer to textbooks. ${ }^{1-5}$

\section{Principles and Advantages of NIR Spectroscopy}

\section{$2 \cdot 1$ Brief history of NIR spectroscopy}

The history of NIR spectroscopy is unclear. At the end of the 19th century, both IR and visible spectra were measured for simple compounds, and thus spectra in the NIR region might also be measured. However, it is uncertain. It was in the 1940's that several papers reporting on NIR spectra were published in scientific journals. ${ }^{1}$ In the 1940's and 1950's, considerable attention was paid to NIR spectroscopy in terms of hydrogen-bonding studies and studies on anharmonicity. The progress of these studies was rather slow, probably because of insufficient availability of spectrometers in the NIR region, and difficulty to conduct spectral analysis.

It was not a spectroscopist, but an agricultural engineer of USDA (United States Department of Agriculture), who awaked "Sleeping Giant" in 1960's. ${ }^{21,22}$ Carl Norris, who is called "Father of NIR spectroscopy", succeeded to employ NIR spectroscopy in quality assessments of agricultural product. ${ }^{21,22}$ He applied statistical methods to develop calibrations using NIR data. His unique idea and the development of computers in the 1960 's and 70's opened the way for practical applications of NIR spectroscopy.

Electronic NIR spectroscopy should have a longer history, because electronic visible spectroscopy has a very long history, and it is difficult and not appropriate to discriminate between electronic visible and electronic NIR spectroscopy. One of the most remarkable epochs in this field was the in vivo monitoring of the redox behavior of cytochrome $c$ oxidase (or cytochrome $\mathrm{aa}_{3}$ ) by Jöbsis in 1997.23 This is the first trial of a biomedical application of NIR spectroscopy.

Following applications to agriculture and food engineering and medical science, applications of NIR spectroscopy spread to various fields, such as polymer and petroleum industry, pharmaceutical industry, and environmental analysis.

The real development of NIR spectroscopy as basic spectroscopy occurred in the 1990's due to rapid progress in NIR spectrometers and spectral-analysis methods. ${ }^{1-10}$ Recent rapid developments of NIR spectrometers, particularly FT-NIR spectrometers, and spectral-analysis methods, like chemometrics, ${ }^{16-20}$ two-dimensional correlation analysis, ${ }^{24,25}$ and quantum chemical calculations, ${ }^{26-28}$ have stimulated novel studies on the overtones and combination modes, as well as their anharmonicities and molecular structure and interactions. ${ }^{1-5}$

For the last five to ten years, much attention has been paid to NIR imaging, portable and hand-held spectrometers, on-line monitoring, PAT (process analysis technology), and medical diagnosis. ${ }^{1-10,12,13}$

\subsection{Principles of NIR spectroscopy}

The IR region is related essentially to the vibrational states of molecules, while the visible region is the region where bands due to electronic transitions appear. In contrast, as mentioned above, NIR spectroscopy is concerned with both electronic transitions and vibrational transitions. It is rather difficult to differentiate between electronic transitions in the visible region and those in the NIR region, although one can say that most of the electronic transitions observed in the NIR region are $d-d$ transitions, charge-transfer (CT) transitions and $\pi-\pi^{*}$ transitions of large, or long, conjugated systems. It is very easy to discriminate the NIR region from the IR region because the former treats only bands due to overtones and combination modes, while the latter is mainly concerned with fundamentals.

Bands due to electronic transitions observed in the NIR region are, in general, weak. Moreover, bands arising from overtones and combination modes are also weak because the overtones and combination modes are so-called forbidden transitions. ${ }^{1-10}$ In reality, the fact that the NIR region is a region of forbidden transitions is what makes this region unique and markedly different from the other regions. In one sense, the reason why the NIR region is valuable is because only the NIR region serves as a highly transmitting window to radiation, while neighboring regions, the ultraviolet region, the visible region, the IR region and the far IR region, are all regions where a number of allowed transitions occur. Therefore, as a generality by comparison, the NIR region transmits light well. In other words, absorption is weak in the NIR region.

The NIR region may be divided into region I $\left(800-1200 \mathrm{~nm} ; 12500-8500 \mathrm{~cm}^{-1}\right)$, region II $(1200-1800 \mathrm{~nm}$; $\left.8500-5500 \mathrm{~cm}^{-1}\right)$ and region III $(1800-2500 \mathrm{~nm} ; 5500-$ $\left.4000 \mathrm{~cm}^{-1}\right)$. The borders of the three regions are not rigorous. Region I is particularly very unique, having several nick names: "the short-wave NIR (SWNIR) region", "near NIR (NNIR) region", or "the Herschel region". This region is a region in which both bands due to electronic transitions and those due to overtones and combination modes are observed. All of the bands appearing in this region are very weak. Thus, region I shows a very high transparency. This region is also called "the window of body". ${ }^{1-10}$ A number of biomedical applications and applications to agricultural products are carried out using this region. It is also in mind that CCD can be used as a detector in this region. Thus, the instruments used in region I are often different from those employed in the other two regions.

In region II, we can observe bands arising from the first overtones of $\mathrm{XH}(\mathrm{X}=\mathrm{C}, \mathrm{O}, \mathrm{N})$ stretching vibrations and various 
types of combination modes of XH vibrations. Region III is a combination-mode region. The "permeability" of region III is comparatively poorer. A wide range of applications to various fields uses region II and region III. Applications to basic science, such as studies on hydrogen bondings and solvent-solute interactions, are also mainly concerned with these two regions.

The characteristics of NIR bands are summarized as follows: Almost all of the following characteristics arise from the fact that NIR spectroscopy is involved in forbidden transitions within the harmonic-oscillator approximation:

(1) NIR bands are far weaker than IR bands (for example, a molar absorption coefficient of water in the NIR region is about $1 / 1000$ of that in the IR region).

(2) Many bands arising from overtones and combination modes overlap each other, and a number of bands due to Fermi resonance appear in the NIR region, and thus the assignment of the NIR bands is not easy, generally.

(3) The NIR region is dominated by bands ascribed to functional groups containing a hydrogen atom (e.g., $\mathrm{OH}, \mathrm{CH}, \mathrm{NH})$. This is partly due to the fact that an anharmonic constant of an $\mathrm{XH}$ bond is large, and partly due to the fact that a fundamental of an $\mathrm{XH}$ stretching vibration has high frequency (XH stretching vibrations appear in a high wavenumber region of IR spectra). We can call NIR spectroscopy "an XH spectroscopic method".

(4) As in the case of an IR spectrum, a hydrogen bond and an interaction between molecules cause a band shift for particular bands. The shift is far larger than that of an IR band.

(5) $\mathrm{OH}$ and $\mathrm{NH}$ stretching bands of monomeric and polymeric species are better separated in the NIR region than in the IR region. Even bands ascribed to free, and terminal $\mathrm{OH}$ and $\mathrm{NH}$ groups of the polymeric species may be clearly differentiated in the NIR region.

(6) Because of the larger anharmonicity, bands ascribed to the first overtones of $\mathrm{OH}$ and $\mathrm{NH}$ stretching modes of monomeric species are enhanced compared with the corresponding bands arising from polymeric species. Therefore, it is often easier to monitor the dissociation process from polymeric species into monomeric ones in the NIR region, rather than in the IR region, by using the first overtone of the $\mathrm{OH}$ or $\mathrm{NH}$ stretching mode of the monomeric species.

\subsection{Advantages of NIR spectroscopy}

Now, we can summarize the characteristics of NIR spectroscopy as follows:

(1) It is powerful in non-destructive analysis and in situ analysis.

(2) Non-contact analysis and analysis using an optical fiber are easily performed by NIR spectroscopy.

(3) It makes it much easier to study and analyze an aqueous solution than where IR light is used.

(4) One can apply NIR spectroscopy to samples in various states, shapes, and thickness.

Now, let us consider the advantages of NIR spectroscopy over IR spectroscopy.

(1) NIR spectroscopy allows the analysis, or in situ analysis with a sample as it originally is. Although non-destructive analysis is possible with IR light, if attenuated total reflection (ATR) or photoacoustic spectroscopy (PAS) is used, there is no other choice than NIR spectroscopy if one wishes to measure an absorption spectrum on the whole of an apple, a pear or a human head, for instance, in a non-destructive manner.
(2) It is possible to set a light-fiber probe in a dangerous environment, and remotely manipulate it. This is one of the reasons why NIR spectroscopy is appropriate to on-line analysis.

(3) NIR spectroscopy is suitable in the analysis of aqueous solutions. Of course, one can examine aqueous solutions with IR spectroscopy. However, NIR spectroscopy permits one to study aqueous solutions in far more various manners. For example, the quantitative analysis of salts contained in a soy-bean sauce and a discriminant analysis of commercially available mineral water.

(4) One can select a light path length very freely. Since the absorption is often too strong in the IR region, only a cell having a very short light path length can be used in IR spectroscopic analysis; a thin film is required, or other restrictions exist with IR spectroscopy. Conversely, NIR spectroscopy allows one to use a $1-\mathrm{cm}$ cell, or even a $10-\mathrm{cm}$ cell, and measure a thick film as it is; it also has other advantages.

\section{Analysis of NIR Spectra}

Also, in spectral-analysis NIR spectroscopy is full of variety. ${ }^{1-10}$ When one analyzes NIR spectra, one should consider the purpose of the spectral analysis: analysis for physicochemical studies, quantitative analysis, classification, online analysis and so on. As in the case of IR and Raman spectroscopy, band assignments give rise to the base for spectral analysis, also in the NIR region. Sometimes, detailed band assignments are very important, but sometimes those are almost nonsense in NIR spectra. In some cases, bands arise from combinations of overtones; and for such cases it is very difficult to make precise band assignments. Also, Fermi resonance causes very complicated spectral patterns, making band assignments almost impossible. However, even in such cases one should know to which functional group a band belongs.

To unravel complicated NIR spectra, conventional band assignment methods and spectral-analysis methods are not always sufficient. Thus, chemometrics has most often been used to extract rich information from NIR spectra. ${ }^{1-10,16-20}$ A main part of chemometrics is multivariate data analysis, which is essential for qualitative and quantitative assays based on NIR spectroscopy. Besides well-known multivariate data analysis methods, such as principal-component analysis/regression (PCA/PCR) and partial least squares regression (PLSR), self-modeling curve resolution (SMCR), which is used to predict pure component spectra and pure component concentration profiles from a set of NIR spectra, is also becoming important. ${ }^{1-10,16-20}$

In addition to the conventional spectral-analysis methods and chemometrics, two-dimensional (2D) correlation spectroscopy has recently been introduced to NIR spectroscopy. ${ }^{24,25}$ In this method spectral peaks are spread over a second dimension to simplify the visualization of complex spectra consisting of many overlapped bands, and to explore any correlation between the bands. Moreover, recently, quantum chemical calculations, such as density function theory (DFT) calculations, are becoming popular, even in NIR spectral analysis. ${ }^{26-28}$ One can calculate the intensities and frequencies of overtones bands using quantum chemistry calculations.

In this way, nowadays we usually use conventional spectral-analysis methods and chemometrics to analyze NIR spectra, depending upon the purposes. One must know that in NIR spectroscopy the original spectra are often subjected to 
pretreatments or data transformation before conducting spectral analysis. ${ }^{1-10,16-20}$ Particularly for NIR spectra of bulk materials, which usually show noise and baseline fluctuations, pretreatments are very important. A variety of pretreatment methods are imposed on the experimental data to reduce any noise, to correct baseline variations, to enhance apparent spectral resolution and/or to normalize the data. The pretreatment methods can be divided into four categories. ${ }^{1-10}$ One method is noise reduction. Smoothing is a representative method for noise reduction. Another method is baseline correction. The second derivative and multiplicative scatter correction (MSC) are most frequently employed for baseline correction. The third method is centering and normalization, and the last is resolution enhancement. Difference spectra, mean centering, and second derivative are used in NIR spectroscopy as resolution enhancement methods.

\subsection{Conventional spectral analysis method}

Conventional band assignment methods, such as those based on group frequencies, spectra-structure relationship, and comparison of the NIR spectrum of a compound with those of related compounds are, of course, very useful for the analysis of NIR spectra. Moreover, general spectral-analysis methods, like second derivative and difference spectra, are employed in NIR spectroscopy.

Conventional spectral analysis methods used in NIR spectroscopy are summarized as follows.

(1) Spectral analysis based on group frequencies:

Tables for group frequencies in the NIR region are available in some NIR textbooks. ${ }^{1,3,4,10}$

(2) Spectra-structure correlations:

One can compare the NIR spectrum of a compound with those of similar compounds. For example, NIR measurements of a series of alcohols allow one to make assignments of bands due to $\mathrm{OH}, \mathrm{CH}_{2}$ and $\mathrm{CH}_{3}$ groups.

(3) Spectral analysis based on perturbation:

Perturbation-dependent spectral changes, such as temperature-dependent, $\quad \mathrm{pH}$-dependent, and concentration-dependent spectra changes, often provide very important information about the band assignments.

(4) Derivative spectra and difference spectra:

Both are useful to unravel overlapping bands and to find out a weak feature hidden by a strong band.

(5) Comparison of an NIR spectrum with the corresponding IR and/or Raman spectrum:

This is, of course, essentially important for band assignments.

(6) Curve fitting:

This is sometimes useful, even for NIR, but care must be taken for curve fitting, because a number of bands are overlapped in the NIR region. Thus, it is often difficult to determine the number of component bands.

(7) Spectral interpretation by polarization measurements

(8) Isotope exchange experiments

(7) and (8) are not conventional spectral analysis methods, but for some special cases, they are useful.

\subsection{Chemometrics}

For the basic principles of chemometrics, one should refer to textbooks. ${ }^{16-20}$ In this section we outline new chemometrics algorithms for wavelength interval selection, which we proposed recently. ${ }^{29,30}$

Chemometrics is an essential tool for analyzing NIR spectra showing complicated overlapping absorption bands. In the construction of a calibration model, PLS regression is the most popular multivariate method. In general, PLS is a powerful

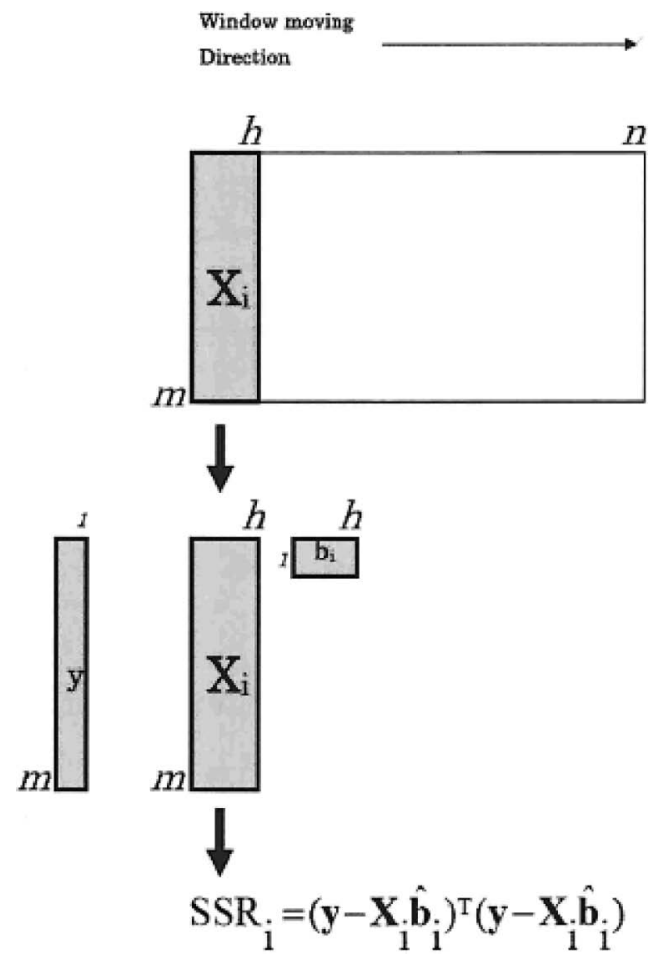

Fig. 1 Scheme for explaining MWPLSR. Reproduced from Ref. 70 with the permission. Copyright (2004) Elsevier.

method, but when it is applied to NIR spectra of very complex samples consisting of a number of components, it does not always yield good results. This is because such NIR spectra usually contain interference signals, such as those due to water and other components. The crucial point for building the best calibration models for the determination of sample components is to select informative NIR regions where one can obtain an optimized calibration model for them. Theoretical ${ }^{31,32}$ and experimental ${ }^{33,34}$ evidence have indicated that wavelength selection can significantly improve the performance of full-spectrum calibration techniques, such as PLS, and various wavelength or wavenumber selection methods have been proposed and used. ${ }^{35-41}$

We developed several new chemometrics algorithms for wavelength interval selection and sample selection in multicomponent spectral analysis. ${ }^{29,30,42,43}$ In this section, recently proposed new wavelength selection methods, moving window partial least squares regression (MWPLSR) (Fig. 1), ${ }^{29}$ changeable size moving window partial least squares (CSMWPLS) (Fig. 2), ${ }^{30}$ and searching combination moving window partial least squares (SCMWPLS) (Fig. 3) $)^{30}$ are outlined. The prediction error of indirect (or inverse) calibration may be inflated by including nonideal spectral regions, and a common feature of the nonideal spectral regions is an increased complexity in latent variable (LV) models when these regions are used for calibration modeling. ${ }^{29} \mathrm{We}$, thus, proposed a new method of spectral interval selection, called MWPLSR. ${ }^{29}$

3.2.1 Moving window partial least squares regression (MWPLSR)

MWPLSR aims at searching for informative spectral regions that contain useful information for PLS model building, and are helpful to improve the performance of the model. ${ }^{29}$ MWPLSR constructs a series of PLS models for all, giving PLS factor numbers (LVs) in a window that moves over the full spectra, 


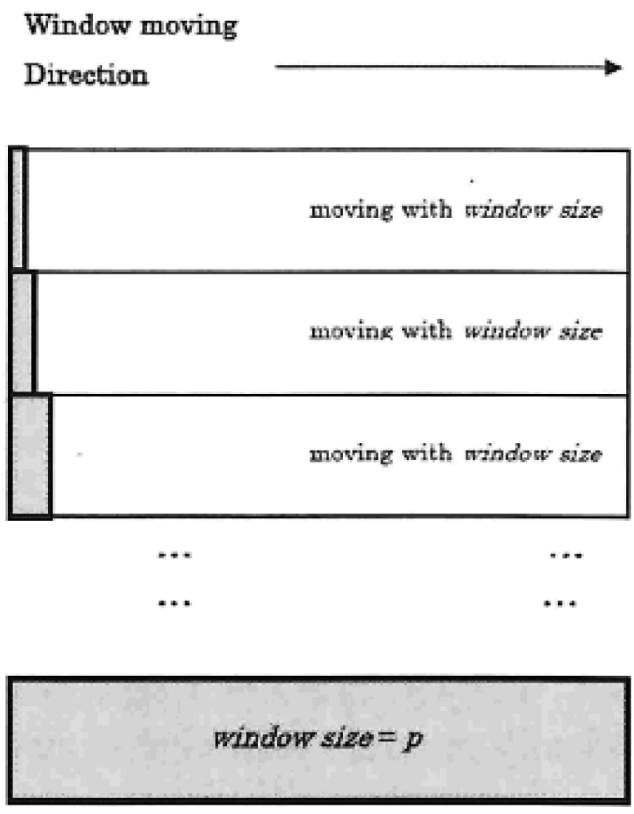

Fig. 2 Scheme for explaining CSMWPLS. Reproduced from Ref. 70 with the permission. Copyright (2004) Elsevier.

and then locates relevant spectral intervals in terms of the least complexity of PLS models reaching a desired error level. In addition, the selection of spectral intervals in terms of the least model complexity enables one to reduce the size of a calibration sample set in calibration modeling.

The MWPLSR algorithm is illustrated in Fig. 1.29 In MWPLSR, a spectral window starting at the $i$ th spectral channel, and ending at the $(I+h-1)$ th spectral channel is constructed, where $h$ is the window size. There are $(n-h+1)$ windows over the whole spectra, each window corresponding to a subset of the original spectral $\mathbf{X}$ ( $m \times n$ matrix; $m$ samples and $n$ spectral channels; see Fig. 1).

The PLS models with different numbers of LVs can then be built to relate the spectra in the window to the concentrations of the analyte, as follows:

$$
\mathbf{y}=\mathbf{X}_{\mathrm{i}} \mathbf{b}_{\mathrm{i}, \mathrm{k}}+\mathbf{e}_{\mathrm{i}, \mathrm{k}}
$$

where $\mathbf{b}_{i, \mathrm{k}}$ ( $h \times 1$ vector) is the regression coefficients vector, estimated by using PLS with $k$ PLS components, and $\mathbf{e}_{\mathrm{i}, \mathrm{k}}$ is the residue vector obtained with $k$ PLS components. The window is moved over the whole spectral region. At each position, PLS models with varying PLS component number are built for the calibration samples, and the log of the sums of squared residues $(\log (\mathrm{SSR}))$ are calculated with these PLS models and plotted as a function of the position of the window. ${ }^{29}$

A representative informative region should show low values of the SSR, and often shows the shape of an upside down peak, corresponding to a band in the same region. Thus, one can easily select the beginning and end points of the region. However, such a selected region possibly does not supply the best predictive results, i.e., this region is not optimum, and possibly there still exists a special sub-region in this region, which may supply the optimum results. Therefore, it is necessary to search for the optimum sub-region for an informative region obtained by MWPLSR in order to further improve the prediction of the PLS model.

In practice, more than one informative region are often found

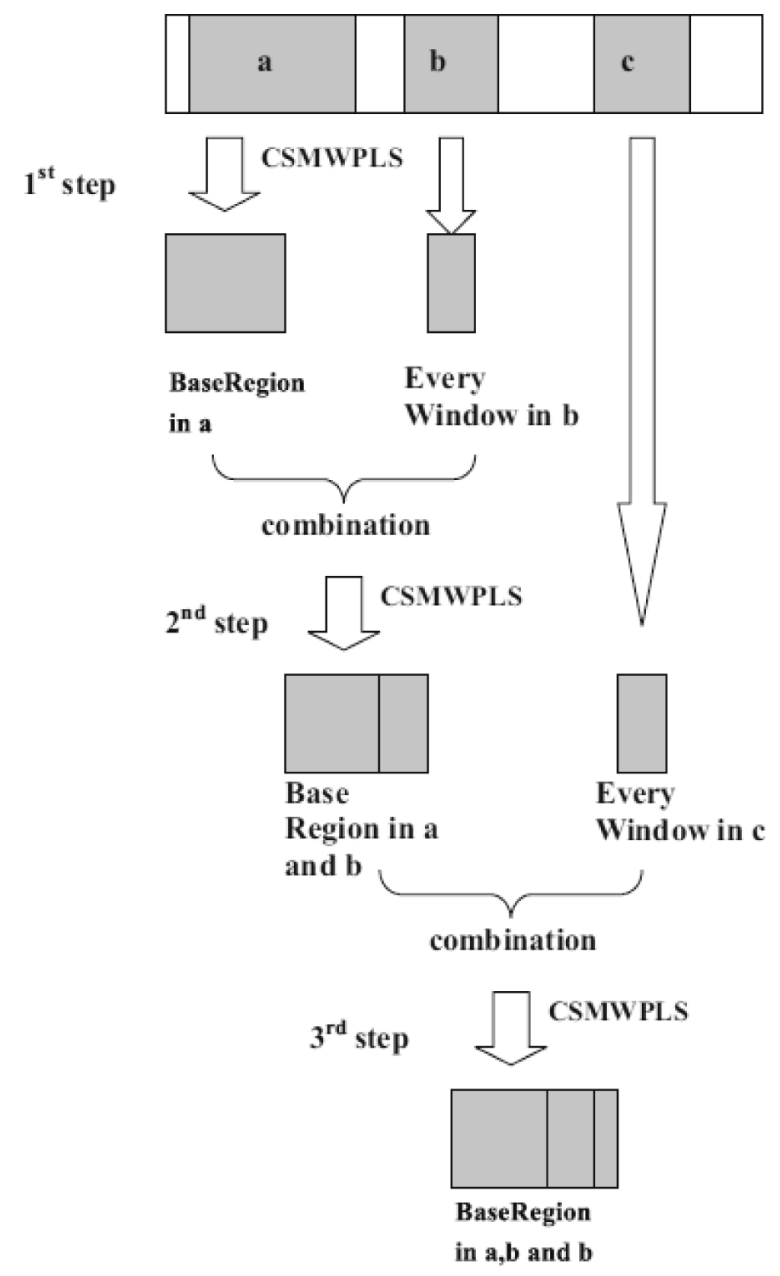

Fig. 3 Scheme for explaining SCMWPLS. Reproduced from Ref. 70 with the permission. Copyright (2004) Elsevier.

by MWPLSR in vibrational spectra, because of the existence of many spectral bands. In such cases, the combination of regions seems to be needed to collect more useful information from the spectra used to construct the PLS models. To search for an optimized sub-region for each selected informative region and the optimized combination of informative regions, we proposed CSMWPLS and SCMWPLS methods. ${ }^{30}$

3.2.2 Changeable size moving window partial least squares (CSMWPLS) and searching combination moving window partial least squares (SCMWPLS)

Figure 2 shows the basic principle of CSMWPLS. In CSMWPLS, the moving window size, $w$, is changed from 1 to $p$ for a given information region with $p$ special pints. ${ }^{30}$ A moving window is moved from the first spectral point to the $(p-w+1)$-th point over the informative region, and to collect all possible sub-windows for every window size (Fig. 2). When $w=1$, moving the window from the first to the end point will collect all possible sub-windows with the window size of one. Similarly, for other cases of $w$, all sub-windows with the size of $w$ may be obtained. Accordingly, CSMWPLS considers all possible spectral intervals (sub-window or sub-regions) in the range of the informative region. For every window, a PLS model with a selected LV number is constructed, and RMSEC is calculated. The sub-region with the smallest value of RMSEC is considered as being the optimized spectral interval.

SCMWPLS searches for the optimal combination of 
informative regions based on CSMWPLS. ${ }^{30}$ Every informative region obtained by MWPLSR contains an optimized sub-region, and these sub-regions are optimum in their corresponding regions, but their direct combination may not develop an optimum performance. Therefore, one should develop a method to search for the optimized combination of informative regions. ${ }^{30}$ An exhaustive search, which considers all possible combinations of spectral points in all informative regions, can guarantee one to find the global optimum. However, a calculation by an exhaustive search will take much more time; even it cannot be finished by a general microcomputer e.g., for a system with three informative regions $\mathrm{a}, \mathrm{b}$ and $\mathrm{c}$ (see Fig. 3), where the numbers of spectral intervals are $a, b$ and $c$, respectively, the number of possible combinations equals to $\frac{a(a+1)}{2} \times \frac{b(b+1)}{2} \times$ $\frac{c(c+1)}{2}$. If $a=40, b=50, c=60$, an exhaustive search method will deal with $\frac{40(40+1)}{2} \times \frac{50(50+1)}{2} \times \frac{60(60+1)}{2}=$ $1.9133 \times 10^{9}$ combinations.

SCMWPLS is a local optimized algorithm used to search for the optimized combination of informative regions. ${ }^{30}$ In the first step of SCMWPLS, CSMWPLS is applied to the first region (region a in Fig. 3) that shows the minimum residue level to search for the optimized sub-region with the smallest value of RMSEC in a reasonable LV number selected by cross validation. This optimized sub-region is viewed as the base-region. The second step is to perform CSMWPLS for the second informative region (region b in Fig. 3), in which one uses combinations of the base-region and one of the possible spectral intervals selected from the second informative region, to build PLS models and to calculate their RMSEC values. After that, a new base-region will be selected, which shows the smallest value of RMSEC. The next step is to look for another new base-region with a similar procedure for the next informative region, until the last informative region. The base-region after finishing calculations for all informative regions, is considered to be the optimized combination. This algorithm only requests one to search for a few parts of all possible combinations of the informative regions, whose number is $\frac{a(a+1)}{2}+\frac{b(b+1)}{2}+\frac{c(c+1)}{2}$ for a system with three informative regions $\mathrm{a}, \mathrm{b}$ and $\mathrm{c}$, where the numbers of spectral intervals are $a, b$ and $c$, respectively. When $a=40, b=50, c=60$, SCMWPLS will deal with only $\frac{40(40+1)}{2}+\frac{50(50+1)}{2}+\frac{60(60+1)}{2}=3925$ combinations.

Recently, MWPLSR, CSMWPLS, and SCMWPLS have been used quite extensively for developing calibration models using NIR data. One good example of their applications is described later (see Sect. 4.4). ${ }^{44-46}$

\section{Application}

The application of NIR spectroscopy is so wide that nowadays it is really impossible to cover all of the application areas in this review. ${ }^{1-10}$ Thus, the following topics were selected: application to polymer studies, on-line monitoring, application of NIR electronic spectroscopy to inorganic functional materials, biomedical applications, and NIR imaging.

\section{4·1 Applications to polymer science and engineering}

NIR spectroscopy has been shown to be a powerful tool for polymer science and engineering. ${ }^{1,9}$ Basically, it provides information about constitution, configuration, conformation, structure, molecular interactions (e.g. hydrogen bonding), and
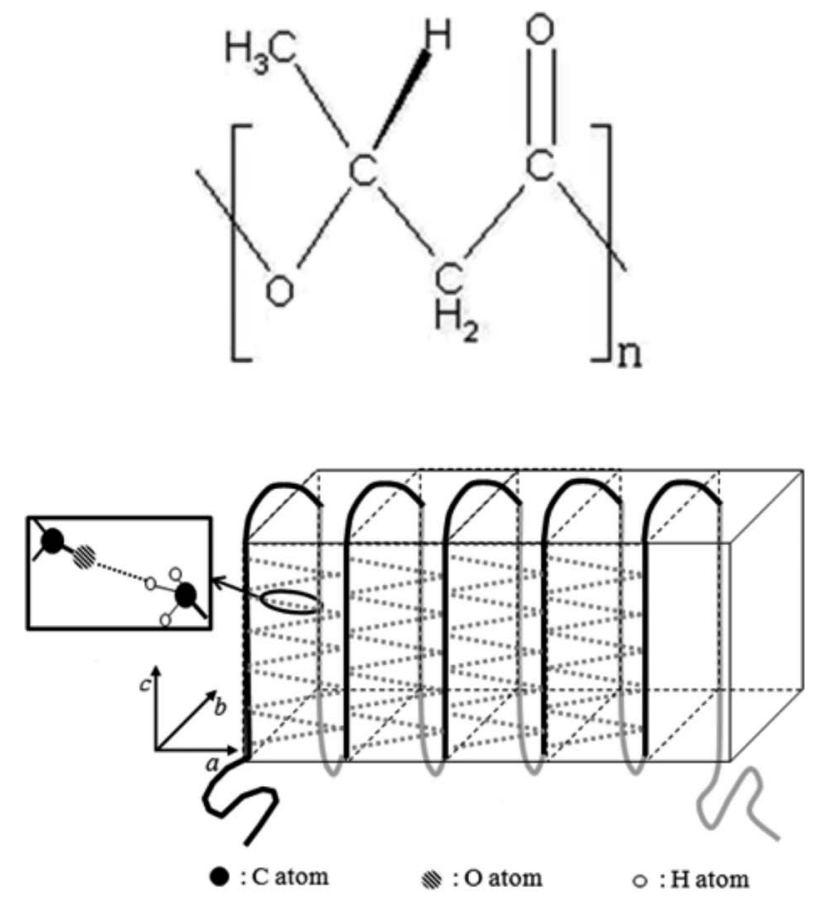

Fig. 4 Chemical and lamella structure of PHB.

physical properties (e.g. crystallinity). One can also employ NIR spectroscopy to monitor a chemical reaction. Thus, it is very useful for both polymer science and engineering. NIR polymer applications are spread widely, from the rheo-optical NIR-spectroscopy of polymers, studies on diffusion of solvent in polymers, on-line monitoring of polymers, to NIR imaging studies. In the following sections an NIR study is introduced on the structure of an environmental-friendly polymer (4.1), applications to one-line monitoring (4.2), and an NIR imaging study on diffusion (4.5).

$\mathrm{Hu}$ et al. ${ }^{47}$ investigated the $\mathrm{C}-\mathrm{H} \cdots \mathrm{O}=\mathrm{C}$ hydrogen bonding and isothermal crystallization of poly(3-hydroxybutyrate) (PHB; Fig. 4) in a thick film at $125^{\circ} \mathrm{C}$ by NIR spectroscopy. PHB is one of the most popular biodegradable polymers; however, it has some disadvantages that limit its practical use. ${ }^{48}$ For example, it is stiff and brittle due to high crystallinity, and its melting temperature is very close to the thermal-decomposition temperature that $\mathrm{PHB}$ becomes thermally unstable during processing. To improve the mechanical and thermal properties of PHB, investigations of the crystalline structure, physical properties, and crystallization and melting behavior of PHB are essentially important. ${ }^{49-51}$

Figure 4 illustrates the crystal and lamella structure of PHB. Recently, Sato et al. ${ }^{52-54}$ investigated the crystallization and melting behavior of PHB by using wide-angle X-ray diffraction (WAXD), IR spectroscopy, and differential scanning calorimetry (DSC). They found that in the IR spectra of PHB, the crystalline $\mathrm{CH}_{3}$ asymmetric stretching band appears at an anomalously high frequency $\left(3009 \mathrm{~cm}^{-1}\right)$, and the crystalline $\mathrm{C}=\mathrm{O}$ band at $1723 \mathrm{~cm}^{-1}$ shows a downward shift compared with the amorphous $\mathrm{C}=\mathrm{O}$ stretching band..$^{52}$ On the basis of these results, together with the shorter distance $(2.63 \AA$ ) between the $\mathrm{O}$ atom of the $\mathrm{C}=\mathrm{O}$ group in one helix structure and the $\mathrm{H}$ atom of one of the three $\mathrm{C}-\mathrm{H}$ bonds of $\mathrm{CH}_{3}$ group in the other helix structure compared with the sum of the van der Waals separation (2.72 $\AA$ ), it was concluded that the $\mathrm{CH}_{3}$ and $\mathrm{C}=\mathrm{O}$ groups of $\mathrm{PHB}$ form a peculiar $\mathrm{C}-\mathrm{H} \cdots \mathrm{O}=\mathrm{C}$ hydrogen bonding that is significantly 

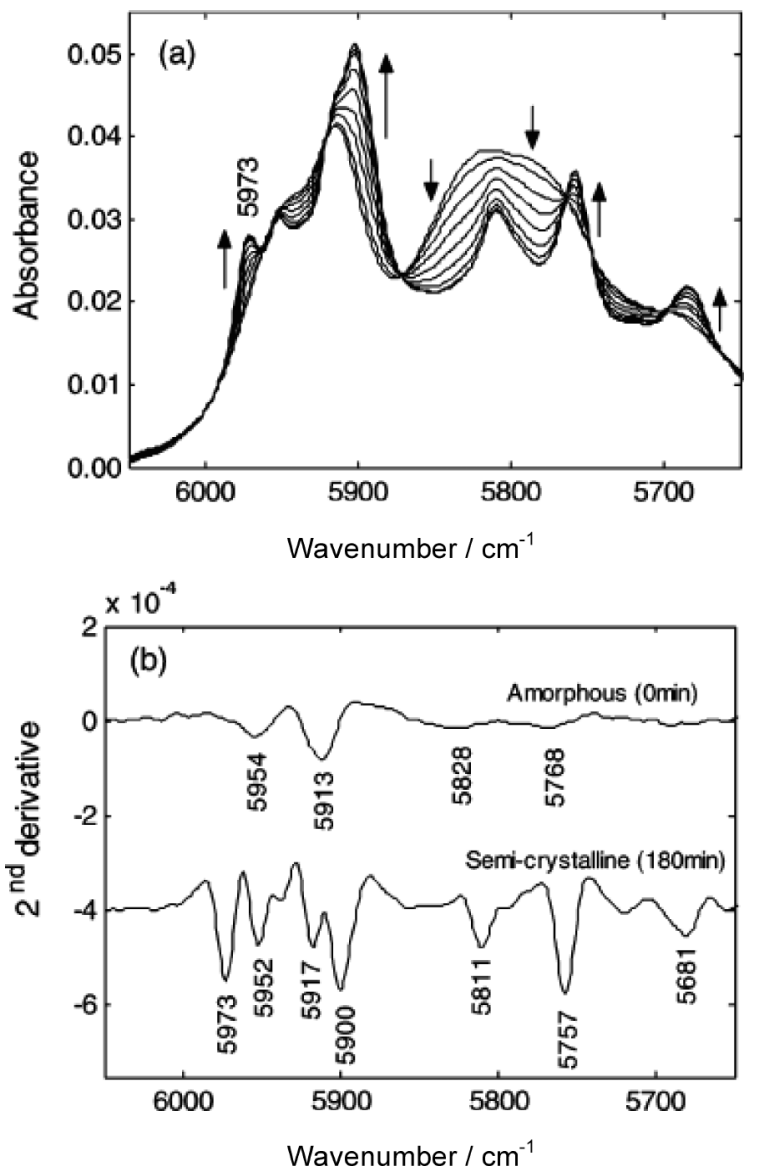

Fig. 5 (a) Temporal changes of NIR spectra in the $6050-5650 \mathrm{~cm}^{-1}$ region of the PHB film $(500 \mu \mathrm{m})$ during the melt-crystallization process at $125^{\circ} \mathrm{C}$. (b) Second derivatives of the spectra measured at 0 and $180 \mathrm{~min}$. Reproduced from Ref. 47 with the permission. Copyright (2006) American Chemical Society.

weaker than normal hydrogen bonding (Fig. 4)..$^{52-54}$

Figure 5(a) shows time-dependent changes in the NIR spectra in the region of $6050-5650 \mathrm{~cm}^{-1}$ of PHB film $(500 \mu \mathrm{m})$ aligned at a 20 -min interval. ${ }^{47}$ Figure $5(\mathrm{~b})$ depicts the second derivatives of the spectra measured at 0 and $180 \mathrm{~min}^{47}$ The second-derivative spectrum measured at 0 min shows four amorphous peaks at around 5954, 5913, 5828, and $5768 \mathrm{~cm}^{-1}$. In contrast, the spectrum of semicrystalline PHB collected at $180 \mathrm{~min}$ shows at least seven bands at 5973, 5952, 5917, 5900, 5811, 5757, and $5681 \mathrm{~cm}^{-1}$ in the same region. Figures 6(a) and 6(b) display the corresponding IR spectra in the $3050-2840 \mathrm{~cm}^{-1}$ region, and the second derivatives of the spectra measured at 0 and $180 \mathrm{~min}$, respectively. It is noted that the temporal NIR spectral variations in the $6050-5650 \mathrm{~cm}^{-1}$ region and the corresponding IR spectral changes in the $3050-2840 \mathrm{~cm}^{-1}$ region show significant similarities. For example, the NIR band with the highest wavenumber at $5973 \mathrm{~cm}^{-1}$ and the corresponding IR band at $3007 \mathrm{~cm}^{-1}$ show similar trends in the temporal changes; both increase with time, suggesting that they arise from the crystalline state.

According to our previous IR study, ${ }^{52-54}$ the unusual high wavenumber shift of the $\mathrm{CH}_{3}$ asymmetric stretching band at $3007 \mathrm{~cm}^{-1}$ indicated the existence of a $\mathrm{C}-\mathrm{H} \cdots \mathrm{O}=\mathrm{C}$ hydrogen bond. Moreover, the $\mathrm{CH}$ stretching band shifts from 2878 to $2873 \mathrm{~cm}^{-1}$ upon the crystallization (Fig. 6(b)), which reflects the conformational transition from the disordered state to the
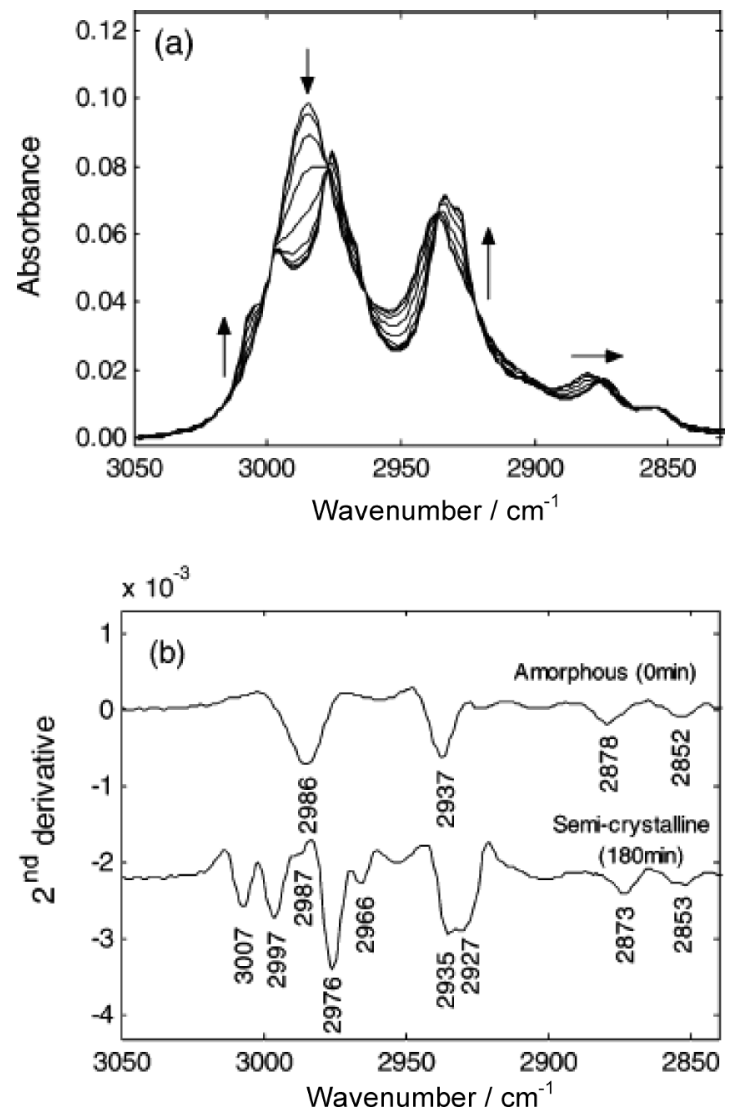

Fig. 6 (a) Temporal changes of IR spectra in the $3050-2840 \mathrm{~cm}^{-1}$ region during the melt-crystallization process of the PHB film at $125^{\circ} \mathrm{C}$. (b) Second derivatives of the spectra measured at 0 and 180 min. Reproduced from Ref. 47 with the permission. Copyright (2006) American Chemical Society.

ordered state. The NIR bands in the $6050-5650 \mathrm{~cm}^{-1}$ region, which are assigned to the first overtones or combination modes of $\mathrm{CH}_{3}, \mathrm{CH}_{2}$, and $\mathrm{CH}$ vibrations, also change markedly with the development of the PHB crystalline structure. These bands are heavily overlapped, and thus the band assignments are not straightforward; however, the band at $5973 \mathrm{~cm}^{-1}$ in the spectrum of the semicrystalline state may be due to the first overtone of the IR band at $3007 \mathrm{~cm}^{-1}$, assigned to the $\mathrm{CH}$ stretching vibration of the $\mathrm{C}-\mathrm{H} \cdots \mathrm{O}=\mathrm{C}$ hydrogen bond.

Figure 7(a) shows the NIR spectra in the region of $5200-$ $5060 \mathrm{~cm}^{-1}$ of PHB during the melt crystallization process. ${ }^{47} \mathrm{~A}$ band at $5127 \mathrm{~cm}^{-1}$ gradually increases with time, while a broad feature centered at $5160 \mathrm{~cm}^{-1}$ decreases during the crystallization process. Thus, $\mathrm{Hu}$ et al. ${ }^{47}$ assigned the former band to the crystalline band and the latter band to the amorphous one. Figure 7(b) depicts the corresponding IR spectra in the 1780 $1670 \mathrm{~cm}^{-1}$ region of $\mathrm{PHB}$, where the bands at 1722 and $1743 \mathrm{~cm}^{-1}$ are assigned to the crystalline and amorphous $\mathrm{C}=\mathrm{O}$ bands, respectively. Based on a comparison of the spectra in Fig. 7(a) with those in Fig. 7(b), Hu et al. ${ }^{47}$ assigned the band at $5127 \mathrm{~cm}^{-1}$ to the second overtone of the $\mathrm{C}=\mathrm{O}$ stretching mode of the $\mathrm{C}-\mathrm{H} \cdots \mathrm{O}=\mathrm{C}$ hydrogen bonding in the crystalline state and the broad feature near $5160 \mathrm{~cm}^{-1}$ to the corresponding band of the amorphous state. The corresponding first overtones are observed at 3435 and $3457 \mathrm{~cm}^{-1}$ in the IR spectra. Using the IR spectral data of the first overtone and fundamental frequencies, they calculated the anharmonicity of the crystalline and amorphous 

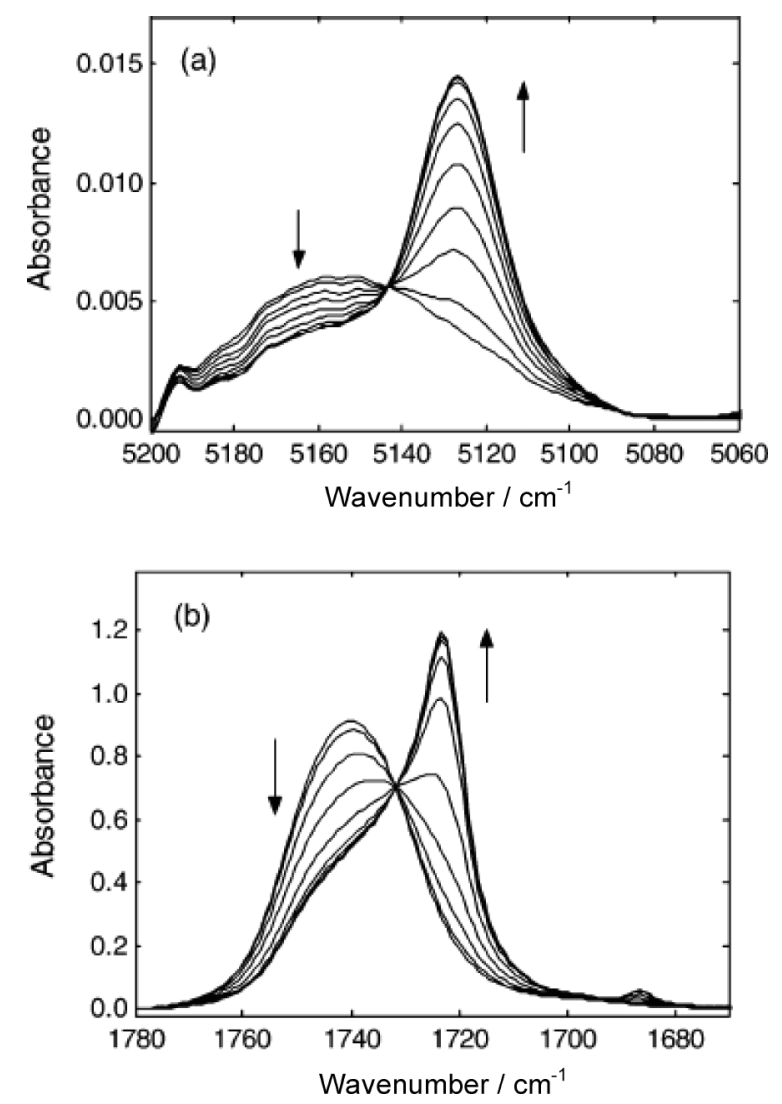

Fig. 7 (a) Temporal changes of NIR spectra in the $5200-5060 \mathrm{~cm}^{-1}$ region during the melt-crystallization process of the PHB film at $125^{\circ} \mathrm{C}$. (b) Temporal changes of IR spectra in the $1780-1670 \mathrm{~cm}^{-1}$ region during the melt-crystallization process of the PHB film at $125^{\circ} \mathrm{C}$. Reproduced from Ref. 47 with the permission. Copyright (2006) American Chemical Society.

$\mathrm{C}=\mathrm{O}$ bands, respectively, to be -4.5 and -14.5 . It was found that the anharmonicity of the crystalline $\mathrm{C}-\mathrm{H}$ and $\mathrm{C}=\mathrm{O}$ bands are largely different from that of the amorphous $\mathrm{C}-\mathrm{H}$ and $\mathrm{C}=\mathrm{O}$ bands. It is very likely that the large variations in the anharmonicity are caused by the formation of the $\mathrm{C}-\mathrm{H} \cdots \mathrm{O}=\mathrm{C}$ hydrogen bonding.

In this way, $\mathrm{Hu}$ et $a l .{ }^{47}$ investigated the $\mathrm{C}-\mathrm{H} \cdots \mathrm{O}=\mathrm{C}$ hydrogen bonding and crystallization dynamics of PHB by using NIR spectroscopy. The spectral changes upon the crystallization process and their band assignments were investigated in detail in each spectral region.

One of the advantages of NIR spectroscopy over IR spectroscopy in polymer studies is that one can investigate the thick film sample, as in the case of this study. This study may become a base for future on-line monitoring of PHB or related polymers.

\subsection{Applications to process analysis}

NIR spectroscopy may be most advanced among various spectroscopic analysis techniques in applications to process analysis. ${ }^{55-58}$ The major reason is that it is excellent in transmittance and well suited for measuring a variety of substances as they are. It can also be used with optical fibers. As a unique technique to "watch" molecules real-time and non-destructively, NIR spectroscopy has the following advantages for on-line analysis:

(1) It allows in situ analysis in a non-destructive manner.
Table 1 Applications of NIR spectroscopy in on-line analysis (revised Table 3.2 of Ref. 55)

Oil refinery applications

Octane number, PINA, PONA, RVP, density, distillation point, etc.

Chemical, petrochemical, and polymer industry applications

Water content, temperature, $\mathrm{OH}$ values, $\mathrm{pH}$ value, concentrations of components, acid value, density, concentration of additive, binder, various reactivities, concentration of solvent, degree of polymerization

Food, bio-process and pharmaceutical applications

Water content, total nitrogen, protein, $\mathrm{OH}$ value, acid value, alcohol, lactose, amino acids, lipid, saccharide, density, degree of fermentation, degree of distillation, salinity

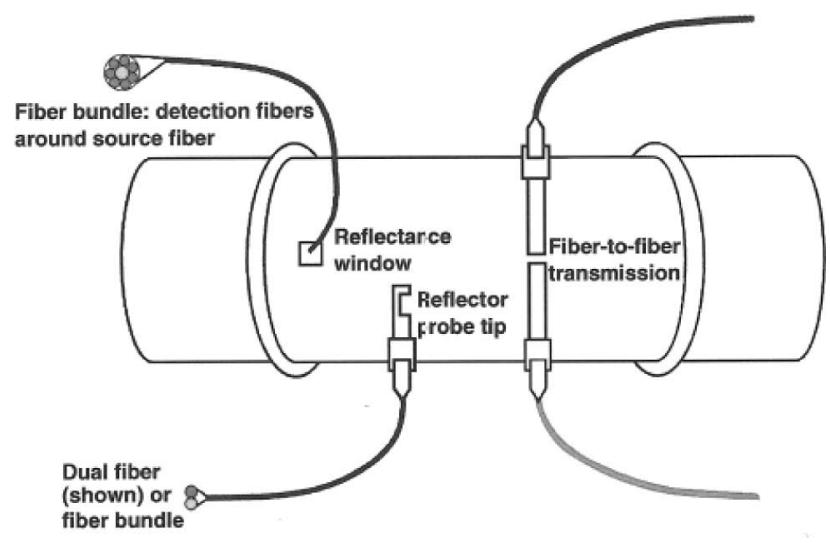

Fig. 8 Examples of system configurations for the respective fields. Reproduced from Ref. 55 with the permission. Copyright (2000) CRC Press.

(2) One can use an optical fiber, and hence it is possible to place a probe in a dangerous environment and remotely control.

(3) The sensitivity and accuracy are very high.

(4) Simultaneous multicomponent analysis on a real-time base is possible; one NIR spectrometer can be used as more than one types of analyzers with changes in calibration curves.

(5) Not only indirect process parameters, such as a flow rate, a temperature and a pressure, but direct parameters as well such as the concentration of a component and physical properties can be measured.

(6) It requires relatively easy maintenance, and has an excellent durability and resistance to environments (e.g., a temperature change, vibrations).

(7) A high cost performance is expected, and it is pollution-free, energy-saving and labor-saving.

\section{4·2・1 Application fields of NIR on-line analysis}

Table 1 plots the application fields of NIR on-line process analysis. ${ }^{55-58}$ Some are already in practical applications, and some are still at an experimental stage. Figure 8 shows three examples of system configurations for the respective fields. ${ }^{55}$ In such systems, an NIR spectrometer serves as a material monitor, a reaction monitor, an intermediate process monitor and a product monitor. Many dedicated-use analyzers installed here and there on the line may be replaced with only one NIR spectrometer. NIR on-line process monitoring is used in petroleum processing, the chemical industry (e.g., polymers, petrochemicals), the food and bio-process industry, and the 
(a)

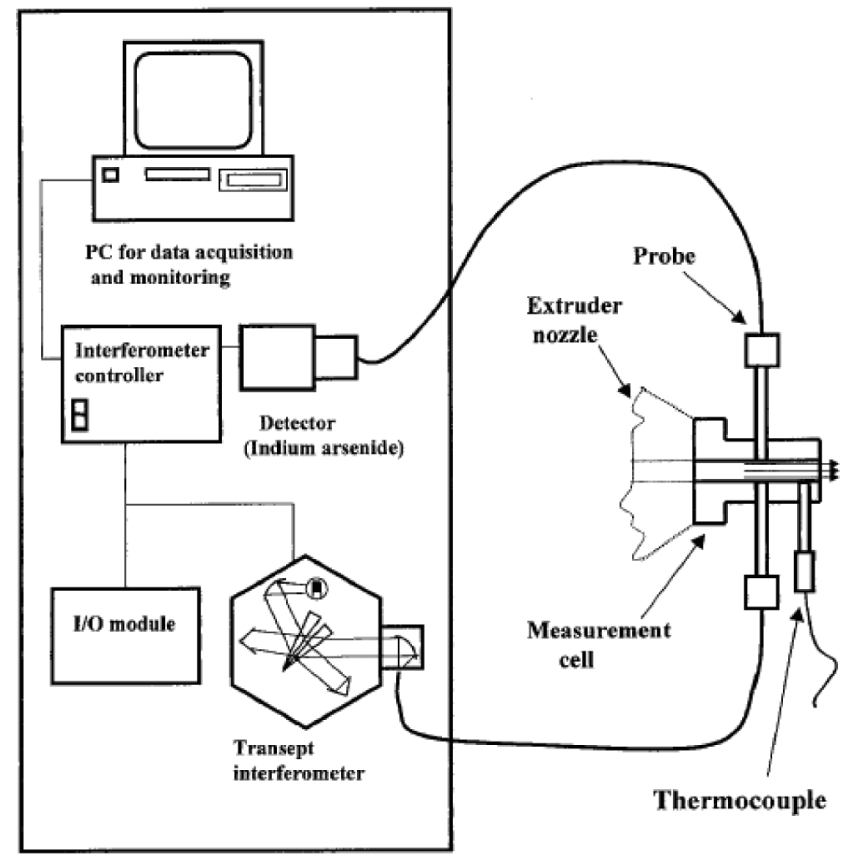

(b)

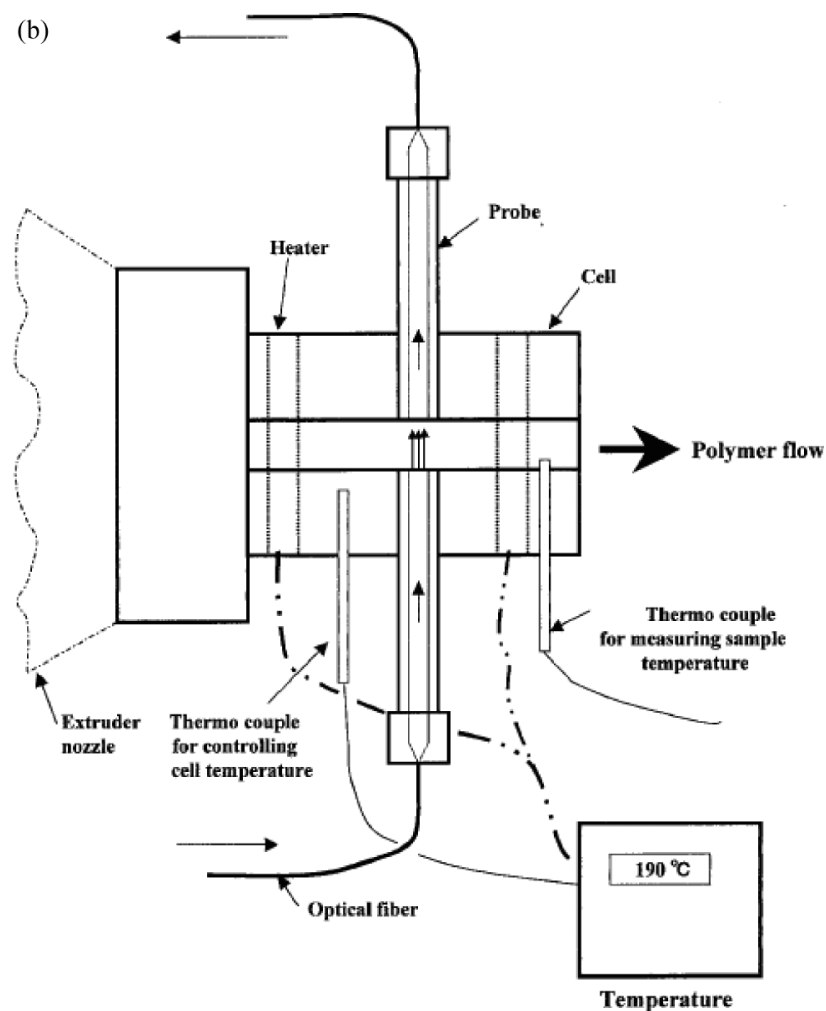

Fig. 9 (a) Schematic diagram of the developed on-line FT-NIR system. (b) A fiber-optic probe and an NIR flow cell for molten polymers. Reproduced from Ref. 59 with the permission. Copyright (2004) Society for Applied Spectroscopy.

pharmaceutical industry (Table 1)..$^{55-58}$ Let us show one good example of NIR on-line monitoring.

$4 \cdot 2 \cdot 2$ On-line monitoring of the density of linear low-density polyethylene by NIR spectroscopy

Watari et al. ${ }^{59}$ reported on-line monitoring of the density of linear low-density polyethylene (LLDPE) by NIR spectroscopy and chemometrics. The density measurement of LLDPE is one of the most important points for the quality control of LLDPE. Thus, if it is possible to monitor the density of LLDPE in real time, it would be very much profitable for process control. Figure 9(a) illustrates the system configuration of the on-line FT-NIR spectrometer developed by Watari et al. ${ }^{59}$ The system consists of an FT-NIR spectrometer (Yokogawa/Analect FIR1000; this includes a Transept type interferometer, an electronically cooled InAs detector, and an interferometer controller), a personal computer, an optical fiber, probes with a sapphire window, and a flow-cell. ${ }^{59}$ A molten polymer stream of LLDPE extruded from an extruder passes through the flow-cell on which the probes are attached from both sides (Fig. 9(b)). The NIR spectra of molten polymers were measured in the transmission mode.

Watari et al..$^{59}$ compared the NIR spectra of LLDPE in melt and solid states before developing a calibration model for predicting the density of LLDPE in a melt state. Solid-state samples were collected at the nozzle of the extruder, and plate samples with a thickness of $1.5 \mathrm{~mm}$ were made from them. The NIR spectra of these samples were compared with those of the molten polymer samples that were measured when the samples for preparing the solid-state samples were taken from the nozzle. Figures 10(a) and 10(b) show a NIR transmittance spectrum and its second derivative, respectively, of the melt-state LLDPE, while Figs. 11(a) and 11(b) depict the corresponding spectra of (a)

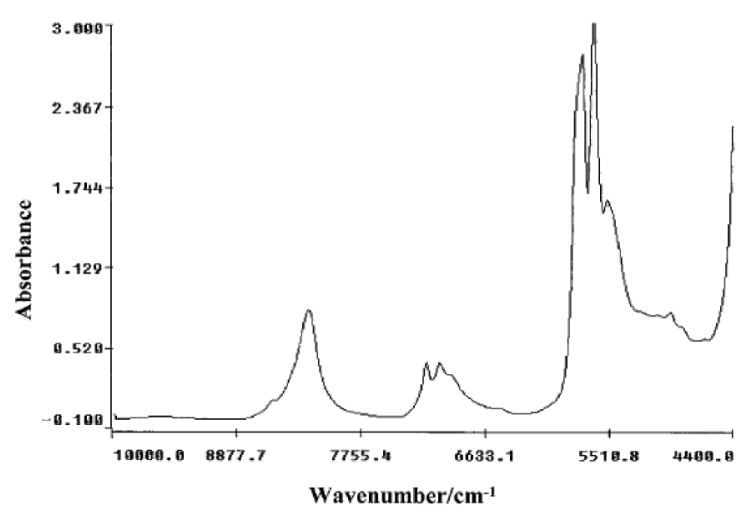

(b)

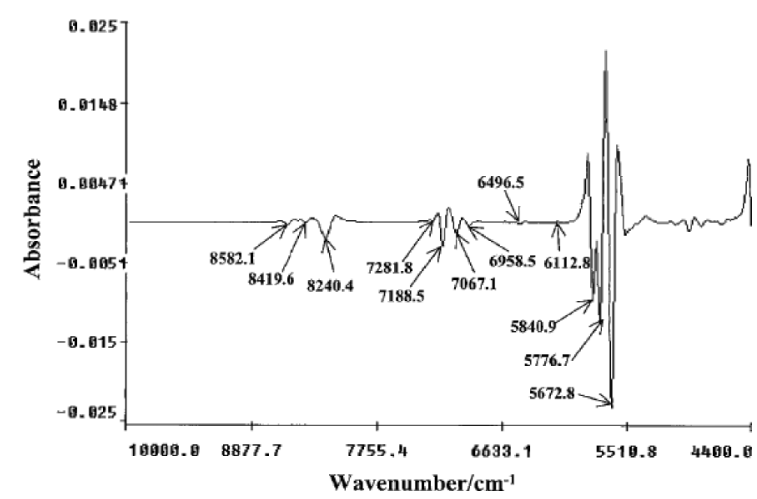

Fig. 10 (a) Example of an NIR spectrum of melt-state LLDPE. (b) Second derivative of the spectrum shown in (a). Reproduced from Ref. 59 with the permission. Copyright (2004) Society for Applied Spectroscopy. 

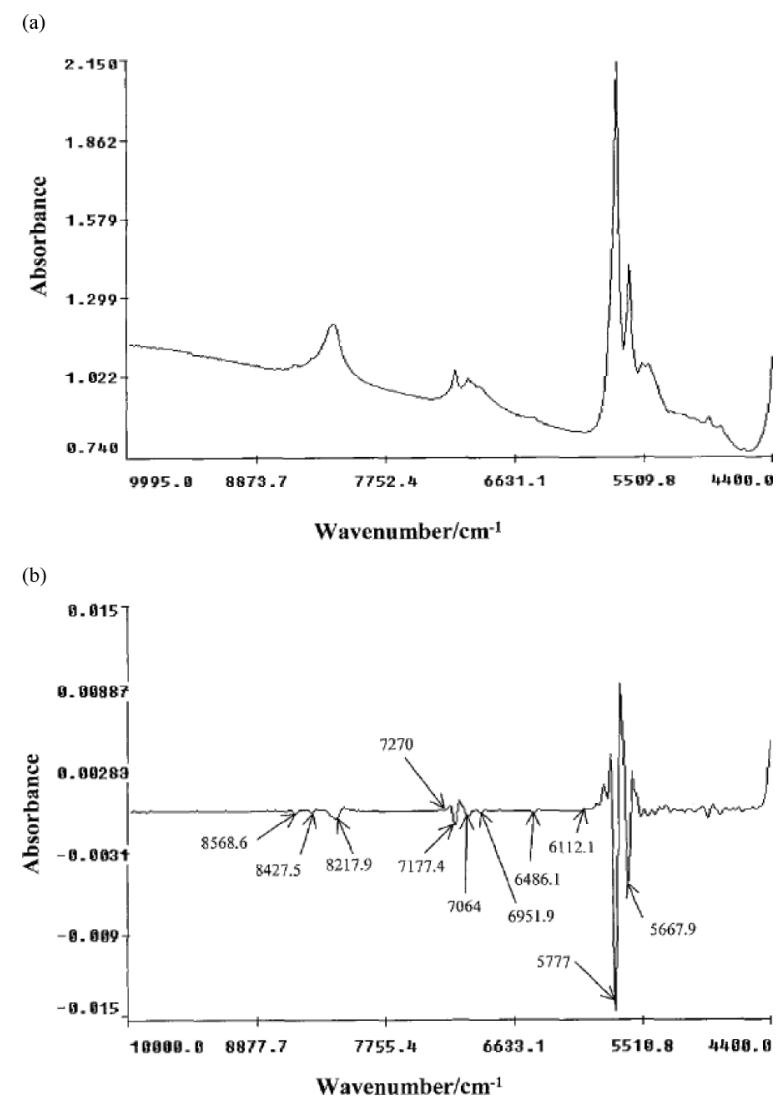

Fig. 11 (a) Example of an NIR spectrum of solid-state LLDPE. (b) Second derivative of the spectrum shown in (a). Reproduced from Ref 59 with the permission. Copyright (2004) Society for Applied Spectroscopy.

Table 2 Band assignments of NIR spectra of LLDPE in melt and solid states (Ref. 59)

\begin{tabular}{lcc}
\hline \multicolumn{1}{c}{ Assignment } & $\begin{array}{c}\text { Melt state } \\
\text { wavenumber/ } \\
\mathrm{cm}^{-1}\end{array}$ & $\begin{array}{c}\text { Solid state } \\
\text { wavenumber/ } \\
\mathrm{cm}^{-1}\end{array}$ \\
\hline $\mathrm{CH}$ str. second overtone $\left(\mathrm{CH}_{2}\right)$ & 8582.1 & 8568.6 \\
$\mathrm{CH}$ str. second overtone $\left(\mathrm{CH}_{3}\right)$ & 8419.6 & 8427.5 \\
$\mathrm{CH}$ str. second overtone $\left(\mathrm{CH}_{2}\right)$ & 8240.4 & 8217.9 \\
$2 \mathrm{CH}$ str. $+\mathrm{CH}$ def $\left(\mathrm{CH}_{3}\right)$ & 7281.8 & 7270 \\
$2 \mathrm{CH}$ str. $+\mathrm{CH}$ def $\left(\mathrm{CH}_{2}\right)$ & 7188.5 & 7177.4 \\
$2 \mathrm{CH}$ str. $+\mathrm{CH}$ def $\left(\mathrm{CH}_{2}\right)$ & 7067.1 & 7064 \\
$2 \mathrm{CH}$ str. $+\mathrm{CH}$ def $\left(\mathrm{CH}_{2}\right)$ & 6958.5 & 6951.9 \\
$\mathrm{CH}$ & 6496.5 & 6486.1 \\
$\mathrm{CH}$ & 6112.8 & 6112.1 \\
$\mathrm{CH}$ & 5840.9 & - \\
$\mathrm{CH}$ str. first overtone $\left(\mathrm{CH}_{2}\right)$ & 5776.7 & 5777 \\
$\mathrm{CH}$ str. first overtone $\left(\mathrm{CH}_{2}\right)$ & 5672.8 & 5667.9 \\
\hline
\end{tabular}

the solid-state LLDPE. ${ }^{59}$ Table 2 summarizes the band assignments for the spectra shown in Figs. 10 and 11.

The NIR spectra of melt- and solid-state LLDPE show significant differences. The most significant difference is found in the $6000-5500 \mathrm{~cm}^{-1}$ region, where bands due to the first overtones and combinations of $\mathrm{CH}_{2}$ antisymmetric and symmetric stretching modes are expected to appear. It is noted that the intensity of a band at $5673 \mathrm{~cm}^{-1}$ is very strong in the spectrum of melt-state LLDPE, while it is much weaker in the spectrum of solid-state LLDPE, and that a band near $5810 \mathrm{~cm}^{-1}$

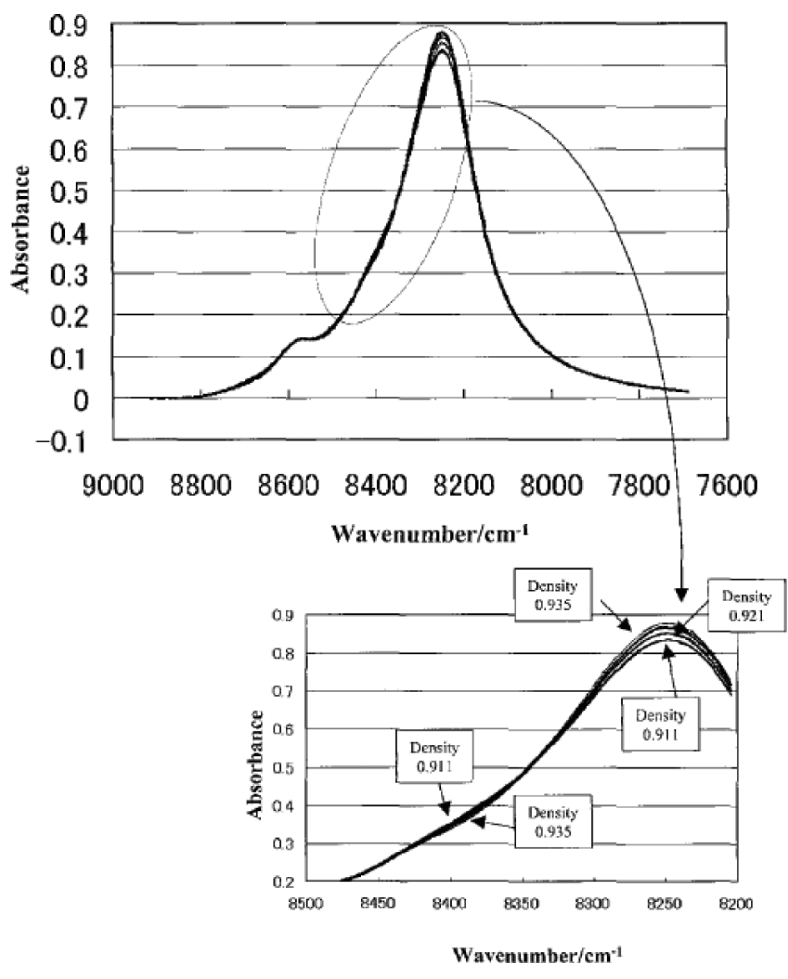

Fig. $12 \mathrm{CH}_{2}$ second overtone region of the NIR spectra of the melt-state LLDPE. Reproduced from Ref. 59 with the permission. Copyright (2004) Society for Applied Spectroscopy.

is split into two bands at 5841 and $5777 \mathrm{~cm}^{-1}$ in the second derivative of the spectrum of the melt-state LLDPE (Fig. 10(b)), while it appears as a singlet peak at $5777 \mathrm{~cm}^{-1}$ in the spectrum of the solid-state LLDPE (Fig. 11(b)). It is known that these bands near 5810 and $5670 \mathrm{~cm}^{-1}$ are very sensitive to the crystallinity of PE. Therefore, the observed differences in the original spectra and their second derivatives between the melt-state and solid-state LLDPE probably reflect the variation in the crystallinity. ${ }^{59}$

Figure 12 displays NIR spectra in the $9000-7680 \mathrm{~cm}^{-1}$ region of seven kinds of LLDPE with different densities. ${ }^{59}$ It is found that with an increase of density, a band at $8240 \mathrm{~cm}^{-1}$ due to the $\mathrm{CH}_{2}$ groups increases, while that near $8390 \mathrm{~cm}^{-1}$, assigned to the $\mathrm{CH}_{3}$ groups, decreases. Table 3 compares the calibration models for predicting the density between the melt-state and solid-state LLDPE. $^{59}$ The models were developed by PLS and cross validation (leave out one sample). Loading plots of Factor 1 are compared between the calibration models for the melt and solid states in Figs. 13(a) and 13(b)..$^{59}$ Figure 13 reveals that there are some significant differences in the peak positions of the Factor 1 loading plots. The loading plot of Factor 1 of the melt samples develops a positive peak near $8250 \mathrm{~cm}^{-1}$ and a negative peak at $8380 \mathrm{~cm}^{-1}$. These wavenumbers are close to those in the spectra shown in Fig. 12.

Watari et al..$^{59}$ reported that the SECV (standard error of cross validation) values of both calibration models are nearly equal. The NIR spectra of LLDPE in the solid state have good correlation with the reference values of the density, because both the spectra of LLDPE plates and the reference values measured by the density gradient tube method reflect the crystallization of LLDPE. However, the results given in Table 3 show that it is also possible to develop the calibration model for the density from the spectra of the melt state using the same samples. 
Table 3 Calibration models for predicting the density of melt- and solid-state LLDPE (Ref. 59)

\begin{tabular}{ccccccccccc}
\hline $\begin{array}{c}\text { Calibration } \\
\text { model }\end{array}$ & Condition & SECV & SEC & $\begin{array}{c}\text { Correlation } \\
\text { coefficient }\end{array}$ & $\begin{array}{c}\text { Number } \\
\text { of sample }\end{array}$ & $\begin{array}{c}\text { Number } \\
\text { of spectra }\end{array}$ & $\begin{array}{c}\text { Leave } \\
\text { out }\end{array}$ & $\begin{array}{c}\text { Number } \\
\text { or factor }\end{array}$ & $\begin{array}{c}\text { Wavenumber } \\
\text { region/ } / \mathrm{cm}^{-1}\end{array}$ & $\begin{array}{c}\text { Density/ } \\
\mathrm{g} \mathrm{cm}^{-3}\end{array}$ \\
\hline LAB1 & Melt & 0.0017 & 0.0011 & 0.993 & 7 & 21 & 3 & 3 & $8998-7687$ & $0.910-0.935$ \\
LAB2 & Solid & 0.0017 & 0.0006 & 0.999 & 7 & 21 & 3 & 4 & $8998-7687$ & $0.910-0.935$ \\
\hline
\end{tabular}

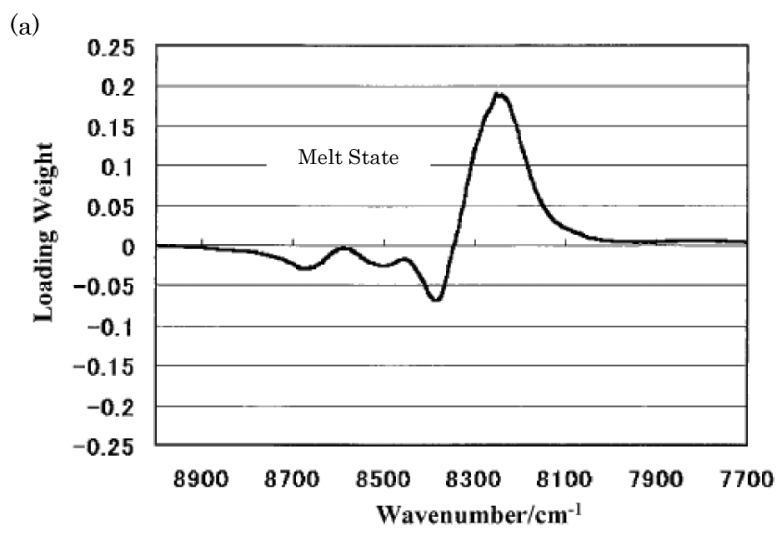

(b)

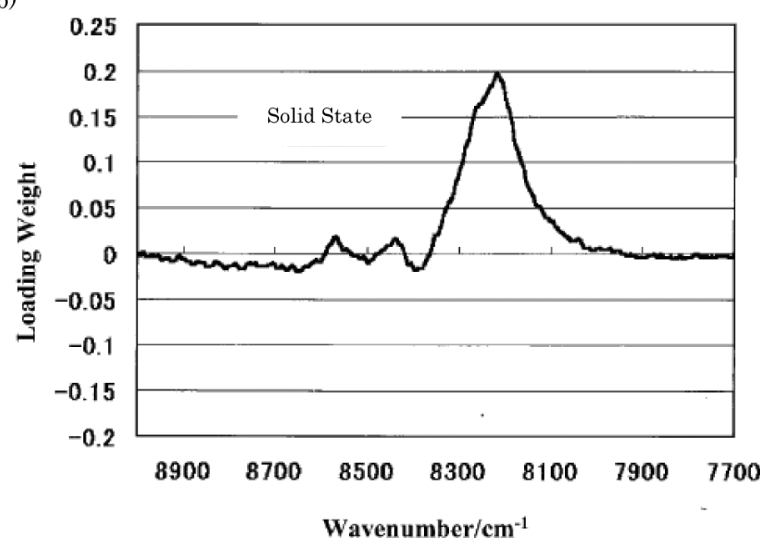

Fig. 13 (a) Loading weight plots of Factor 1 for calibration models that predict the density of the (a) melt-state and (b) solid-state LLDPE. Reproduced from Ref. 59 with the permission. Copyright (2004) Society for Applied Spectroscopy.

Watari et al. ${ }^{60,61}$ also investigated the prediction of the ethylene content in melt-state random polypropylene and block polypropylene and that of the vinyl acetate concentration in ethylene-vinyl acetate copolymers by using NIR spectroscopy and chemometrics. They also proposed calibration transfer methods for process analysis by NIR spectroscopy. ${ }^{62}$

\subsection{Applications of NIR electronic spectroscopy to inorganic functional materials}

As mentioned in previous sections, NIR spectroscopy can be divided into NIR vibrational spectroscopy and NIR electronic spectroscopy. Thus far, most of applications of NIR spectroscopy are based on NIR vibrational spectroscopy, while those of NIR electronic spectroscopy are relatively limited, except for particular regions, like biomedical applications..$^{5,8,11-15}$ It is also noted that NIR spectroscopy has usually been applied to organic, polymeric and biological materials, while applications to inorganic materials are rather rare. ${ }^{12,14,15}$ The following example provides novel potential of NIR electronic spectroscopy in the qualitative and quantitative monitoring of a chemical reaction of inorganic functional material. (a)

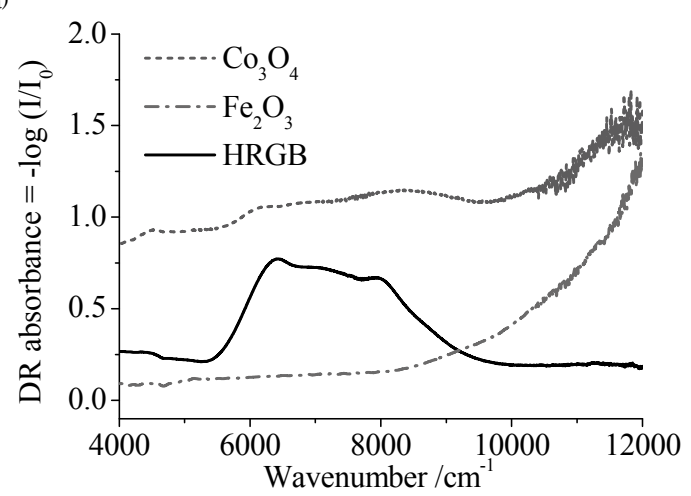

(b)

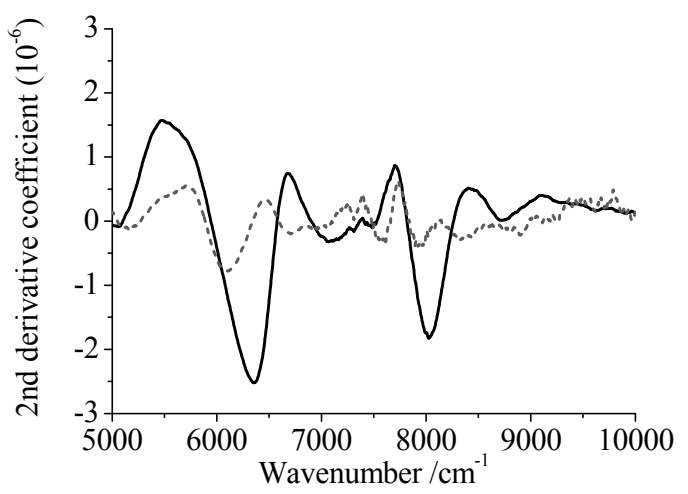

Fig. 14 (a) NIR DR spectra in the $12000-4000 \mathrm{~cm}^{-1}$ region of powders of $\mathrm{HRGB}, \mathrm{Co}_{3} \mathrm{O}_{4}$, and $\alpha-\mathrm{Fe}_{2} \mathrm{O}_{3}$. (b) Second derivatives of the NIR DR spectra of powders of $\mathrm{HRGB}, \mathrm{Co}_{3} \mathrm{O}_{4}$, and $\alpha-\mathrm{Fe}_{2} \mathrm{O}_{3}$ in the $10000-5000 \mathrm{~cm}^{-1}$ region. Reproduced from Ref. 63 with the permission. Copyright (2012) Society for Applied Spectroscopy.

4.3.1 Quantitative and qualitative monitoring of a calcination reaction of high reflective green-black (HRGB) pigments by using NIR electronic spectroscopy

Morisawa et al..$^{63}$ demonstrated the potential of NIR electronic spectroscopy in nondestructive monitoring of a chemical reaction of inorganic functional material. They measured NIR spectra in the $12000-4000 \mathrm{~cm}^{-1}$ region of high reflective green-black (HRGB; $\mathrm{Co}_{0.5} \mathrm{Mg}_{0.5} \mathrm{Fe}_{0.5} \mathrm{Al}_{1.5} \mathrm{O}_{4}$ ) pigments calcined at 1000,1100 , and $1200^{\circ} \mathrm{C}$ and the pigments that have the same components as HRGB, but were calcined below $1000^{\circ} \mathrm{C}(500-$ $900^{\circ} \mathrm{C}$ ) (hereafter, I call these pigments, Pigments A). The HRGB pigment developed at Toda Kogyo Co. (Hiroshima, Japan) shows black color, but it absorbs little sunlight. ${ }^{63}$ In contrast to normal black pigments, this pigment shows considerable reflectivity in the NIR region if the pigment is applied to a white surface. Its raw materials are $\mathrm{Fe}_{2} \mathrm{O}_{3}, \mathrm{Al}(\mathrm{OH})_{3}$, $\mathrm{Mg}(\mathrm{OH})_{2}$, and $\mathrm{CoCO}_{3}$. It is very important to explore the crystal structure of the components of the pigment and its transmittance characteristics based on the absorptions that are responsible for the decrease in the reflectivity.

Figures 14(a) and 14(b) show NIR DR spectra in the 12000 - 
$4000 \mathrm{~cm}^{-1}$ region and their second-derivative spectra in the $10000-5000 \mathrm{~cm}^{-1}$ region of powders of HRGB, $\mathrm{Co}_{3} \mathrm{O}_{4}$, and $\alpha-\mathrm{Fe}_{2} \mathrm{O}_{3}$, respectively. ${ }^{63}$ The second-derivative spectra reveal that HRGB shows bands at 6354, 7069, 7590 and $8024 \mathrm{~cm}^{-1}$ and that $\mathrm{Co}_{3} \mathrm{O}_{4}$, which has a similar spinel structure to HRGB, shows those at $6094,6713,7569,7951$, and $8320 \mathrm{~cm}^{-1}$. The above bands of $\mathrm{Co}_{3} \mathrm{O}_{4}$ are assigned to $d$ - $d$ transitions, ${ }^{4} A_{2} \rightarrow{ }^{4} T_{1}$, of $\mathrm{Co}(\mathrm{II})$ at a tetrahedral cite. ${ }^{64,65}$ A NIR DR spectrum of $\alpha-\mathrm{Fe}_{2} \mathrm{O}_{3}$ shows a long tail feature in the region of $12000-$ $10000 \mathrm{~cm}^{-1}$ due to a charge-transfer (CT) transition that has maxima at 17000 and $14000 \mathrm{~cm}^{-1}{ }^{6}{ }^{6}$ HRGB shows characteristic peaks of $\mathrm{Co}$ (II) in spinel structure, but it is noted that HRGB does not yield a tail, due to $\mathrm{Fe}(\mathrm{III})$.

NIR DR spectra of HRGB calcined at 1000,1100 , and $1200^{\circ} \mathrm{C}$ and Pigments A calcined below $1000^{\circ} \mathrm{C}\left(500-900^{\circ} \mathrm{C}\right)$ are shown in Fig. 15.63 It is noted in Fig. 15 that the three components of the d-d transition band of $\mathrm{Co}(\mathrm{II})$ in the 9000 $6000 \mathrm{~cm}^{-1}$ region show a significant lower wavenumber shift upon going from 900 to $1000^{\circ} \mathrm{C}$, and that the CT band of Fe(III) decreases markedly.

Table 4 summarizes NIR bands of Pigments A calcined at 500 and $900^{\circ} \mathrm{C}$, and $\mathrm{HRGB}$ and $\mathrm{Co}_{3} \mathrm{O}_{4}$. Referring to WAXD data of HRGB and Pigments A, Morisawa et al. ${ }^{63}$ have assigned the bands at 6541,7529 , and $8208 \mathrm{~cm}^{-1}$ of Pigments A calcined in the temperature range of $500-900^{\circ} \mathrm{C}$ to $\mathrm{AB}_{2}^{\prime} \mathrm{O}_{4}(\mathrm{~A} \equiv \mathrm{Co}$ (II), $\left.\mathrm{Mg}(\mathrm{II}) ; \mathrm{B}^{\prime} \equiv \mathrm{Al}(\mathrm{III})\right)$ with spinel structure and those at 5924,

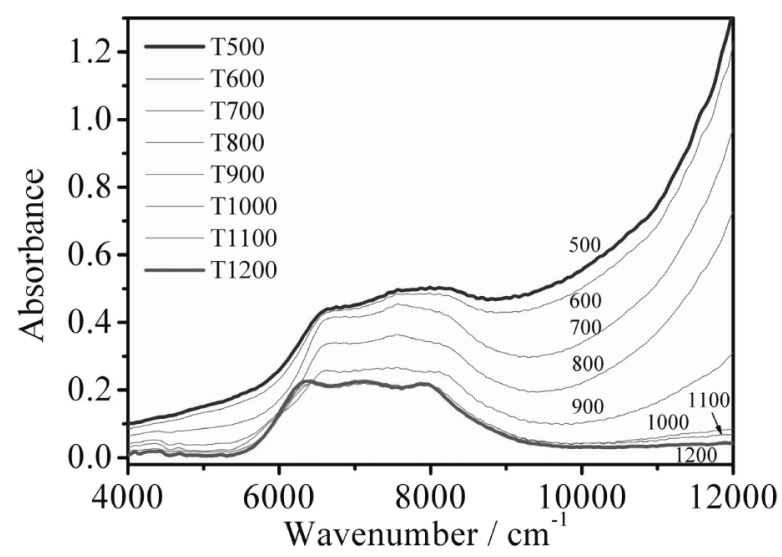

Fig. 15 NIR DR spectra of HRGB calcined at 1000, 1100, and $1200^{\circ} \mathrm{C}$ and Pigments A calcined below $\left(500-900^{\circ} \mathrm{C}\right)$. Reproduced from Ref. 63 with the permission. Copyright (2012) Society for Applied Spectroscopy.
7220 , and $8208 \mathrm{~cm}^{-1}$ of Pigments A calcined in the temperature range of $700-900^{\circ} \mathrm{C}$ to $\left(\mathrm{A}_{1-\mathrm{x}} \mathrm{B}_{\mathrm{x}}\right)^{\mathrm{Th}}\left(\mathrm{A}_{\mathrm{x}} \mathrm{B}_{2-\mathrm{x}}\right)^{\mathrm{Oh}} \mathrm{O}_{4}(\mathrm{~A} \equiv \mathrm{Co}, \mathrm{Mg}$, $\mathrm{B} \equiv \mathrm{Fe}, \mathrm{Al})$ having an inverse spinel structure.

By comparing calcination temperature-dependent NIR data with the corresponding WAXD data, Morisawa et al. ${ }^{63}$ revealed that the intensity of the CT band of $\mathrm{Fe}(\mathrm{III})$ in the NIR spectra (Fig. 15) decreases with a decrease the $\alpha-\mathrm{Fe}_{2} \mathrm{O}_{3}$ crystal in the pigments (Pigments $\mathrm{A}$ and $\mathrm{HRGB}$ ). Therefore, it was found that when $\alpha-\mathrm{Fe}_{2} \mathrm{O}_{3}$ is mixed with $\mathrm{MgO}$ and $\mathrm{Al}_{2} \mathrm{O}_{3},\left(\mathrm{~A}_{1-\mathrm{x}} \mathrm{B}_{\mathrm{x}}\right)^{\mathrm{Th}}\left(\mathrm{A}_{\mathrm{x}} \mathrm{B}_{2-\mathrm{x}}\right)^{\mathrm{Oh}} \mathrm{O}^{4}$ and $\mathrm{AB}_{2} \mathrm{O}_{4}(\mathrm{~A}=\mathrm{Co}(\mathrm{II}), \mathrm{Mg}(\mathrm{II}) ; \mathrm{B}=\mathrm{Fe}(\mathrm{III}), \mathrm{Al}(\mathrm{III}))$ are formed through $\mathrm{AB}_{2}{ }_{2} \mathrm{O}_{4}(\mathrm{~A}=\mathrm{Co}(\mathrm{II}), \mathrm{Mg}(\mathrm{II}) ; \mathrm{B}=\mathrm{Al}(\mathrm{III}))$.

The CT band is due to the transition between $\mathrm{Fe}(\mathrm{III})$ atoms at the neighboring $\mathrm{O}$ (II) in the octahedral site of $\alpha-\mathrm{Fe}_{2} \mathrm{O}_{3}$, and it shifts to a higher wavenumber by $2500-2000 \mathrm{~cm}^{-1}$ in a spinel structure. Therefore, upon going from a hematite structure of $\alpha-\mathrm{Fe}_{2} \mathrm{O}_{3}$ to spinel and inverse spinel structures, the lower wavenumber side of the CT band decreases in intensity. ${ }^{14}$ On the other hand, the inter-atomic $d$ - $d$ transition of $\mathrm{Fe}(\mathrm{III})$ of $\alpha-\mathrm{Fe}_{3} \mathrm{O}_{4}$ is observed at $11614 \mathrm{~cm}^{-1}$ as a pseudo-Gauss line shape. It has been known that the $d$ - $d$ transition of Fe(III) at the octahedral site in the spinel structure is observed at a lower wavenumber than that in $\alpha-\mathrm{Fe}_{3} \mathrm{O}_{4}$. Because of the component ratio of $\mathrm{Al}(\mathrm{III}): \mathrm{Fe}(\mathrm{III})=3: 1$ in $\mathrm{HRGB}$, more $\mathrm{Al}(\mathrm{III})$ enters at the octahedral $\mathrm{Fe}(\mathrm{III})$, and each $\mathrm{Fe}$ (III) becomes increasingly separated; the $d$ - $d$ band in HRGB disappears. Therefore, one can monitor the progress of the calcination reaction by using the intensity of the tail region of the CT band.

Morisawa et al. ${ }^{63}$ developed a PLS calibration model for the calcination reaction temperature by using the second-derivative NIR spectra in the $12000-4000 \mathrm{~cm}^{-1}$ region of HRGB and Pigments A. Loading plots along with the wavenumber for LV1, LV2 and LV3 of the calibration model are shown in Fig. 16(a), and score plots along with calcination temperature for LV1 and LV2 are depicted in Figs. 16(b) and 16(c), respectively. ${ }^{63}$ Interestingly, they found that the negative peaks in LV1 correspond to the peaks in the second-derivative spectra of HRGB calcined in the temperature range of $1000-1200^{\circ} \mathrm{C}$, and that its positive peaks correspond to the peaks in the second-derivative spectra of Pigments A calcined in the temperature range of $500-900^{\circ} \mathrm{C}$. Accordingly, it seems that the scores of LV1 reflect the decrease in the initial products and the increase in the final products. LV2 plots yield a downward peak near $5900 \mathrm{~cm}^{-1}$, corresponding to a peak in the second-derivative spectrum at $900^{\circ} \mathrm{C}$, assigned to the intermediate material $\left(\left(\mathrm{A}_{1-\mathrm{x}} \mathrm{B}_{\mathrm{x}}\right)^{\mathrm{Th}}\left(\mathrm{A}_{\mathrm{x}} \mathrm{B}_{2-\mathrm{x}}\right)^{\mathrm{Oh}} \mathrm{O}_{4}\right.$; inverse spinel structure). Therefore, the PLS result reveals the existence of an intermediate. The score plots for LV1 and LV2 show the extent of the calcination reaction. It is noted that the behavior of the intermediate $\left(\left(\mathrm{A}_{1-\mathrm{x}} \mathrm{B}_{\mathrm{x}}\right)^{\mathrm{Th}}\left(\mathrm{A}_{\mathrm{x}} \mathrm{B}_{2-\mathrm{x}}\right)^{\mathrm{Oh}} \mathrm{O}_{4}\right)$ in the calcination process

Table 4 Positions of NIR electronic absorption bands of Pigments A calcined at 500 and $900^{\circ} \mathrm{C}, \mathrm{HRGB}$, and $\mathrm{Co}_{3} \mathrm{O}_{4}\left(\mathrm{Ref}^{6}\right.$ 63)

\begin{tabular}{|c|c|c|c|c|c|}
\hline & Pigment A & Pigment A & HRGB(TR) & HRGB(DR) & $\mathrm{Co}_{3} \mathrm{O}_{4}(\mathrm{DR})$ \\
\hline Measured temp. & Room temp. & Room temp. & Room temp. & Room temp. & Room temp. \\
\hline Calcination $T /{ }^{\circ} \mathrm{C}$ & $500-900$ & $700-900$ & $1000-1200$ & 1100 & \\
\hline Structure & Spinel & Inv. spinel & Spinel & Spinel & Spinel \\
\hline \multirow[t]{5}{*}{ Cobalt cite } & $\mathrm{Th}^{\mathrm{a}}$ & $\mathrm{Th} / \mathrm{Oh}^{\mathrm{b}}$ & Th & $\mathrm{Th}$ & $\mathrm{Th} / \mathrm{Oh}$ \\
\hline & 6541 & 5924 & 6264 & 6354 & 6109 \\
\hline & & & & 7069 & 6746 \\
\hline & 7529 & 7220 & 7128 & 7590 & 7536 \\
\hline & 8208 & 8208 & 7992 & 8024 & 8360 \\
\hline
\end{tabular}

a. Co(II) exists in a tetrahedral site. b. Co(II) exists in both tetrahedral site and octahedral site. 


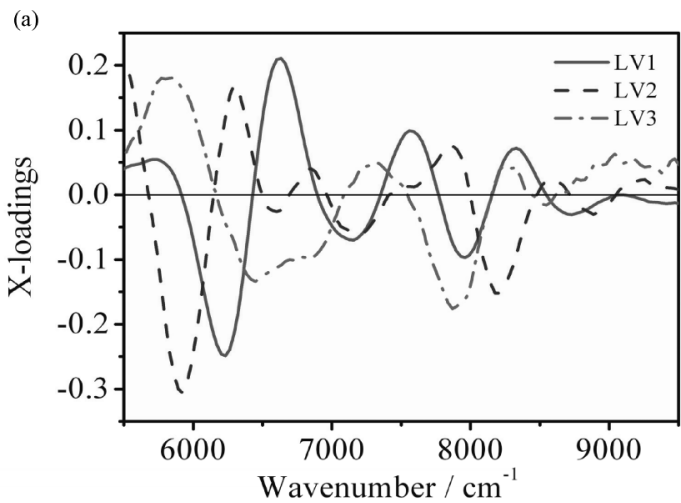

(b)

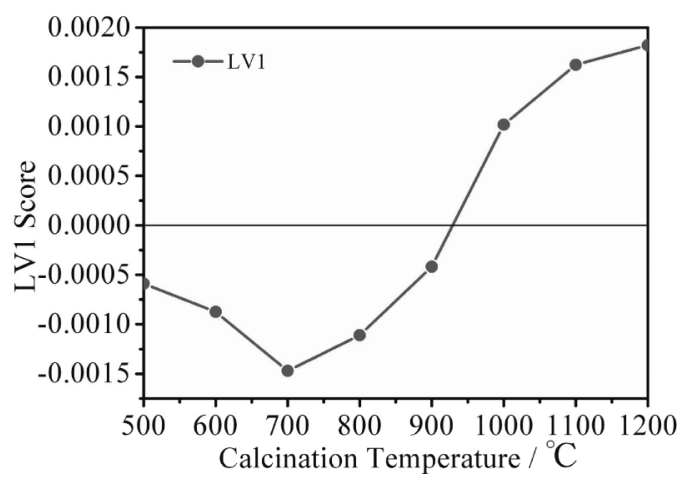

(c)

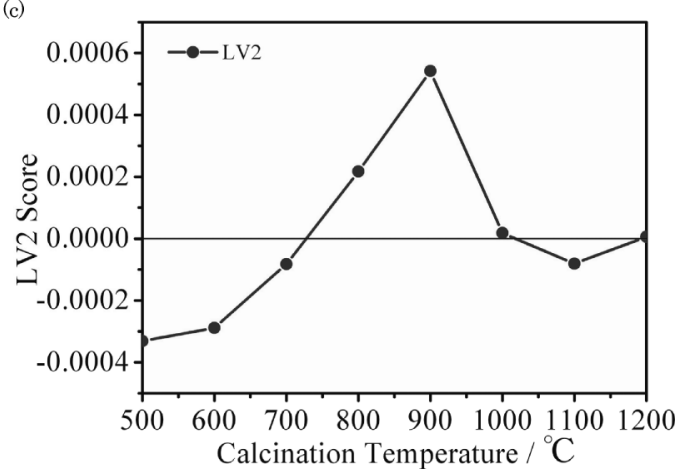

Fig. 16 (a) Loading plots for LV1, LV2 and LV3 of the PLS calibration model developed using the second derivative NIR data of HRGB and Pigments A. (b), (c) Score plots for (b) LV1 and (c) LV2 of the PLS calibration model. Reproduced from Ref. 63 with the permission. Copyright (2012) Society for Applied Spectroscopy.

is distinctly monitored in the LV2 score plot; the intermediate appears in the $800-900^{\circ} \mathrm{C}$ range

In this study it was demonstrated that NIR spectroscopy is powerful in qualitative and quantitative monitoring of calcination reaction of functional inorganic materials. The study also provided new insight into the development of chemometrics calibration models for NIR electronic spectroscopy of complicated inorganic compounds. ${ }^{63}$

\section{4·4 Biomedical applications}

Because NIR spectroscopy is an non-invasive analytical tool, applications to in vivo biomedical analysis and diagnosis have received keen interest. ${ }^{1,5,9,12,13,67-69}$ Particularly, non-invasive brain function analysis and noninvasive blood glucose measurement have been matters of extensive NIR studies. In this section, the non-invasive measurement of blood glucose by NIR DR spectroscopy is outlined.

$4 \cdot 4 \cdot 1$ In vivo non-invasive measurement of blood glucose by near-infrared diffuse-reflectance spectroscopy

NIR spectroscopy has been known to have a potential for realizing noninvasive blood glucose monitoring, and NIR noninvasive blood glucose assay has been investigated extensively for many years. ${ }^{67-78}$ Robinson et al. ${ }^{71}$ and Muller et $a .^{72}$ used a shorter wavelength NIR region, i.e. the region between 800 and $1300 \mathrm{~nm}$ (or $1350 \mathrm{~nm}$ for Muller et al. ${ }^{72}$ ) for finger DR spectra measurements. Robinson et al. ${ }^{71}$ reported that a cross-validated average absolute error of $1.1 \mathrm{mmol} / \mathrm{l}$ $(19.8 \mathrm{mg} / \mathrm{dl})$ was obtained from their calibration model. Muller et al. ${ }^{72}$ obtained the cross-validated root mean standard error of prediction (RMSEP) from $1.02 \mathrm{mmol} / \mathrm{l} \quad(18.4 \mathrm{mg} / \mathrm{dl})$ to $1.88 \mathrm{mmol} / \mathrm{l}(33.8 \mathrm{mg} / \mathrm{dl})$. Heise et al. ${ }^{73-75}$ carried out intensively the in vivo determination of glucose on a single diabetic using a glucose tolerance test, and that on a population of 133 different subjects. They measured the DR of NIR light at the oral mucosa. The RMSEP for the prediction of glucose they obtained was $36.4 \mathrm{mg} / \mathrm{dl}$.

Non-invasive NIR blood glucose monitoring is very challenging project, since it deals with very weak signals of glucose directly from human skin; also the physiological conditions of skin tissue, such as body temperature, vary easily with time. ${ }^{67,68}$ One critical difficulty associated with in vivo blood glucose assay is an extremely low signal-to-noise ratio $(S / N)$ of a glucose peak in an NIR spectrum of human skin tissue. In an in vitro study using NIR transmittance spectroscopy, if one measures the difference of $10 \mathrm{mg} / \mathrm{dl}$ glucose using a $1 \mathrm{~mm}$ cell, one will obtain an absorbance change of less than $10 \mu \mathrm{AU}$ (absorbance unit). ${ }^{67,68}$ This means that background noise easily hides the glucose signal when an NIR spectrum is measured in vivo. Therefore, the quality of spectra is critical for a reliable assay of blood glucose.

To overcome the difficulties mentioned above, Maruo et al. ${ }^{76,77}$ developed a new NIR system that can detect very weak glucose signals in human tissue, and realize a noninvasive blood glucose measurement. The region of 1300 to $1900 \mathrm{~nm}$ was chosen for the NIR measurements. The maximum light path length of the $1300-1900 \mathrm{~nm}$ region is expected to be a few $\mathrm{mm}$, due to strong absorption of water contained in human tissue. For this limitation, the skin tissue, which has a simple anatomical structure with only a few $\mathrm{mm}$ in depth, may be the most suitable for blood glucose monitoring among the various human tissues.

Figure 17 illustrates the developed NIR system for non-invasive blood glucose measurements. ${ }^{76}$ The system consists of a tungsten halogen lamp $(150 \mathrm{~W})$, an optical fiber bundle, switching device for selecting a light path, a flat field-type grating, a $256 \mathrm{In}$ GaAs photodiode array sensor extended to a cut-off $2100 \mathrm{~nm}$, a 16-bit A/D converter and a signal processor. For more details about the developed system, Fig. 18 shows the concept of a blood glucose measurement and a schematic diagram of the cross-section of human skin tissue. ${ }^{76}$ It consists of three layers, i.e. the epidermis, dermis and subcutaneous tissue. There are well-developed capillary vessels in the dermis, and blood glucose is easily transferred to the dermis tissue due to its high permeability. Thus, the glucose content in the dermis is assumed to be correlated with the blood glucose content in the same way as that in the interstitial fluid. If NIR spectra could be obtained selectively from the dermis, the interference noise originating from the epidermis or subcutaneous tissue would be largely removed. The developed system has two optical fibers to obtain the dermis spectra selectively. ${ }^{76}$ One set of optical fibers is attached to the skin 


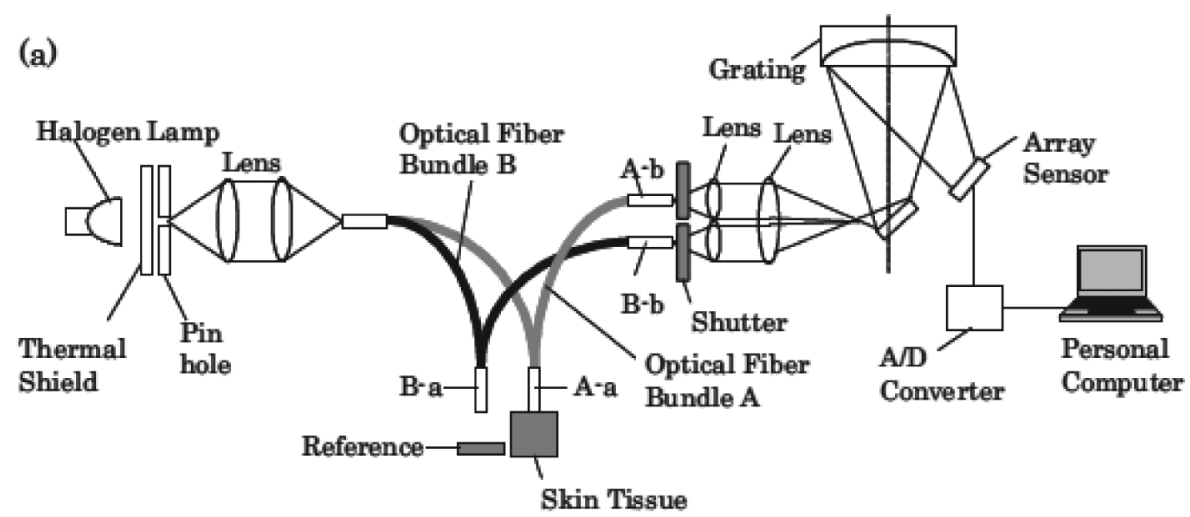

(b)
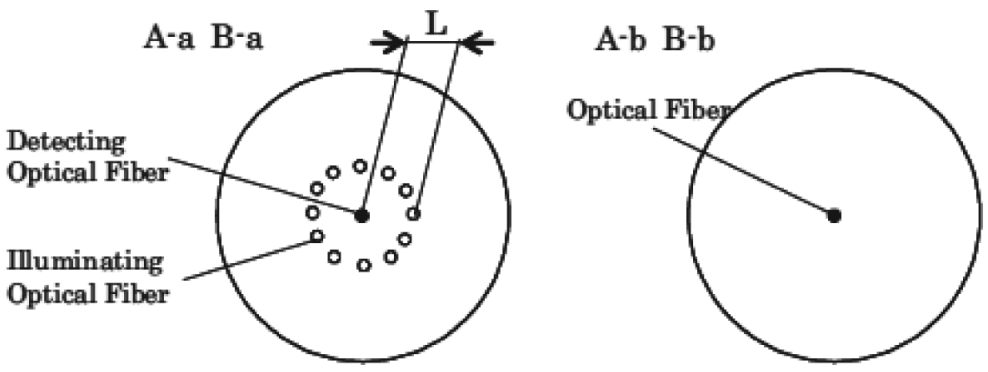

Fig. 17 (a) Schematic diagram of the instrument developed in the study. (b) Schematic diagram of the cross section of the sensing ends A and B. Reproduced from Ref. 76 with the permission. Copyright (2003) IEEE.

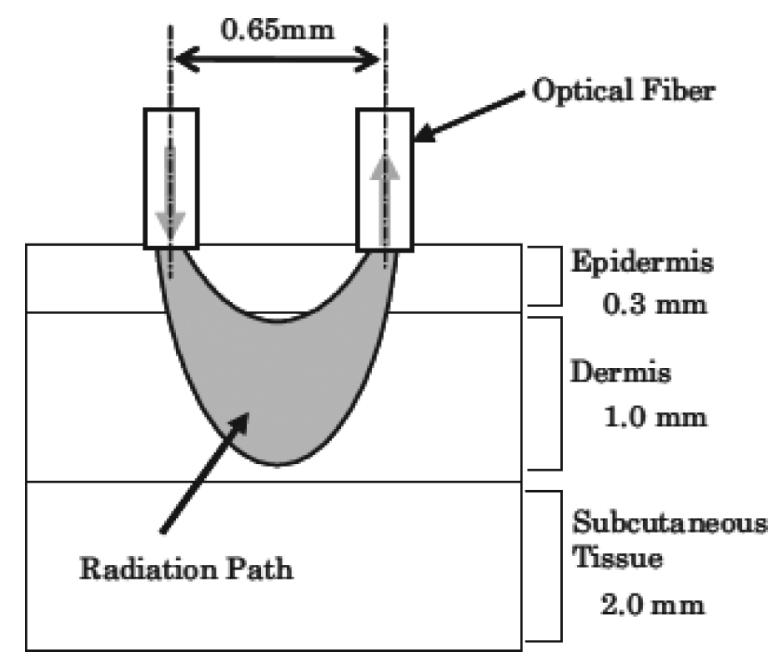

Fig. 18 Concept of blood glucose measurement: Schematic diagram of the cross-section of skin tissue and light path. Reproduced from Ref. 76 with the permission. Copyright (2003) IEEE.

surface vertically; the skin surface is illuminated by the measuring light through the inlet optical fiber, and the scattering light is collected by the detecting fiber. When one chooses an adequate fiber distance, it becomes possible to control the penetration depth of the measuring light.

Figure 19 shows normalized NIR spectra of glucose powder (solid line) and human skin measured noninvasively (dash line). ${ }^{79}$ The latter spectrum was calculated by averaging 48 skin spectra collected during an oral glucose tolerance test. Spectral features due to blood glucose are interfered significantly with those due to water and other components in the skin. Wavelength

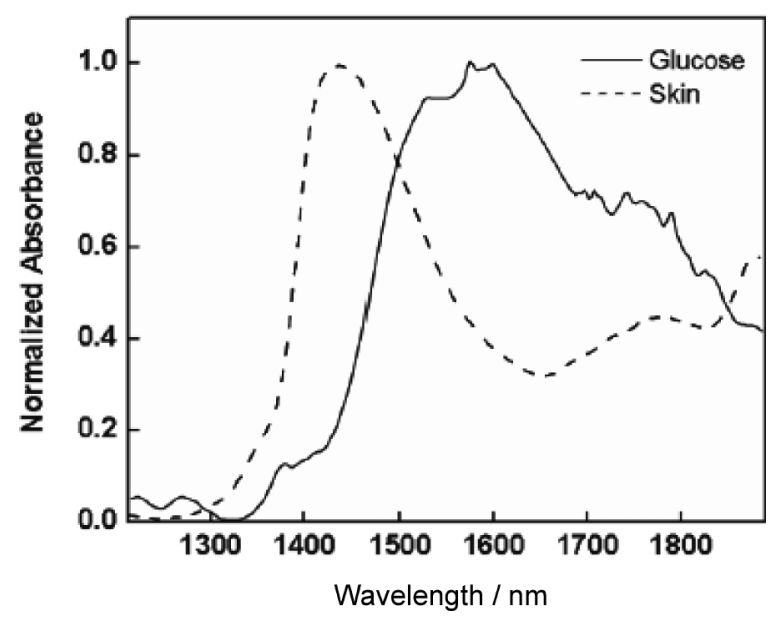

Fig. 19 A normalized NIR spectrum in the $1212-1889 \mathrm{~nm}$ region of glucose powder ( - ) and a normalized averaged of 48 human skin spectra (-----) measured during an oral glucose tolerance test. Reproduced from Ref. 79 with the permission. Copyright (2006) Elsevier.

selection methods are very useful to deal with such problems of the interferences. Therefore, Kasemsumran et al. ${ }^{79}$ applied MWPLSR and SCMWPLS to the in vivo NIR spectra of skin for blood glucose assay.

The original spectra were subjected to MSC before MWPLSR and SCMWPLS were applied. All of the 48 skin spectra were employed to build PLS calibration models. The model performance was validated by using the four segments cross-validation method (12 spectra per each segment) and RMSEV was calculated.

Figure 20 displays 15 residue lines for blood glucose obtained 


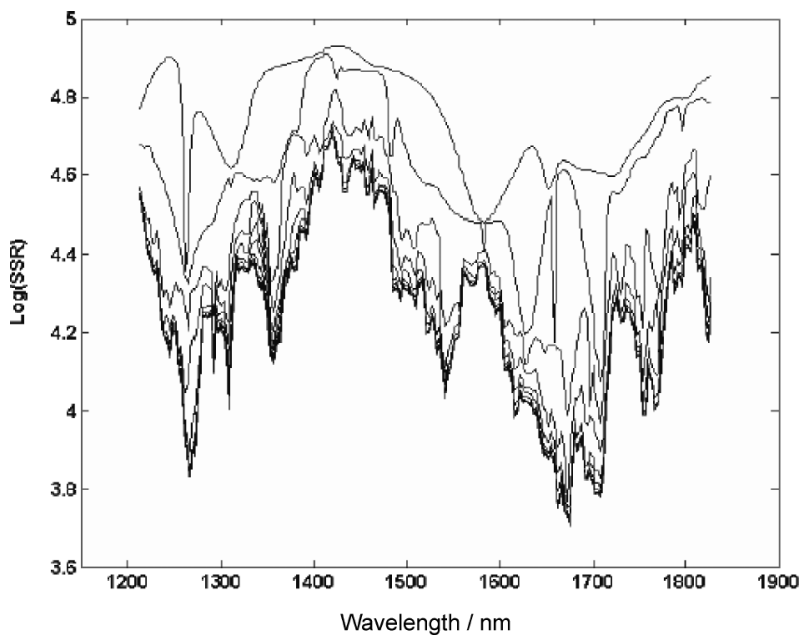

Fig. 20 Residue lines obtained by MWPLSR for the NIR spectra of skin. Reproduced from Ref. 79 with the permission. Copyright (2006) Elsevier.

Table 5 Prediction results for PLS calibration models for blood glucose determination developed by use of the whole spectral region and the regions selected by MWPLSR and SCMWPLS (Ref. 79)

\begin{tabular}{lcccc}
\hline Method & $\begin{array}{c}\text { Spectral region/ } \\
\mathrm{nm}\end{array}$ & $\begin{array}{c}\text { PLS } \\
\text { factor }\end{array}$ & $\begin{array}{c}\text { Correlation } \\
\text { coefficient }\end{array}$ & $\begin{array}{c}\text { RMSEV/ } \\
\mathrm{mg} \mathrm{dl}^{-1}\end{array}$ \\
\hline Whole region & $1212-1889$ & 7 & 0.8936 & 20.1977 \\
MWPLSR & $1228-1323$ & 6 & 0.8519 & 24.2398 \\
MWPLSR & $1574-1736$ & 4 & 0.9091 & 18.3642 \\
MWPLSR & $1739-1800$ & 4 & 0.8302 & 24.8947 \\
MWPLSR & $1228-1323$, & 6 & 0.8840 & 20.9073 \\
& $1574-1736$, & & & \\
MWPLSR & $1739-1800$ & & & \\
& $1228-1323$, & 6 & 0.8984 & 19.4118 \\
MWPLSR & $1574-1736$ & & & \\
& $1574-1736$, & 5 & 0.9060 & 18.7775 \\
SCMWPLS & $1739-1800$ & & & \\
\hline
\end{tabular}

by applying MWPLSR to the NIR spectra of skin. ${ }^{79}$ Three informative regions (the 1228 - 1323, 1574 - 1736, and 1739 $800 \mathrm{~nm}$ regions) can easily be found. The informative regions of $1574-1736$ and $1739-1800 \mathrm{~nm}$ contain bands due to the first overtones of the $\mathrm{OH}$ and $\mathrm{CH}$ stretching modes of glucose, respectively. The region of $1228-1323 \mathrm{~nm}$ has only a weak absorption feature, due to glucose, but it has weak interference from water. SCMWPLS was applied to these three informative regions for optimizing the combination of informative regions. It was found that the optimized combination obtained by SCMWPLS contains only one informative region, i.e., the $1574-1736 \mathrm{~nm}$ region.

Table 5 compares statistical results of blood glucose models built by using the whole region, the individual informative regions, their direct combinations, and the optimized informative region. ${ }^{79}$ It can be seen from Table 5 that the PLS calibration model based on SCMWPLS using the best optimized informative region of $1616-1733 \mathrm{~nm}$ yields the best validation results with the highest correlation coefficient of 0.9205 and the lowest RMSEV of $17.1924 \mathrm{mg} / \mathrm{dl}$ with a PLS factor of $4 .{ }^{79}$ The significant improvement in the validation results shows that this optimized region selected by SCMWPLS contains more

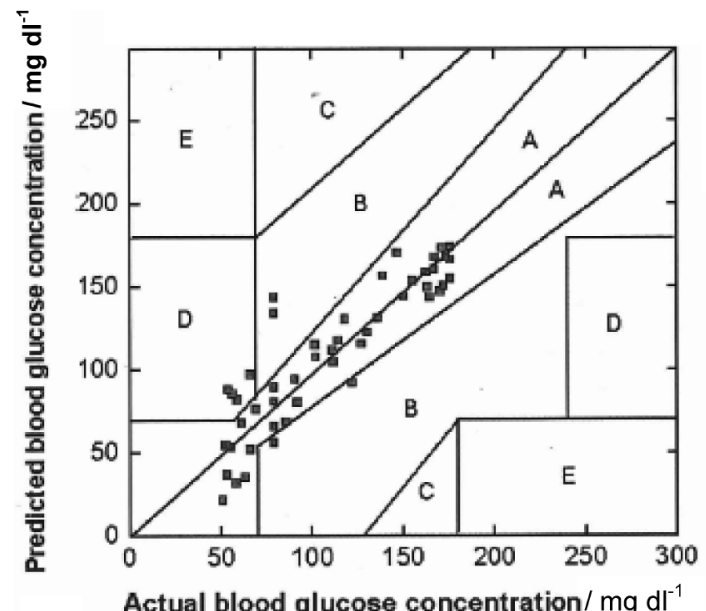

(a)

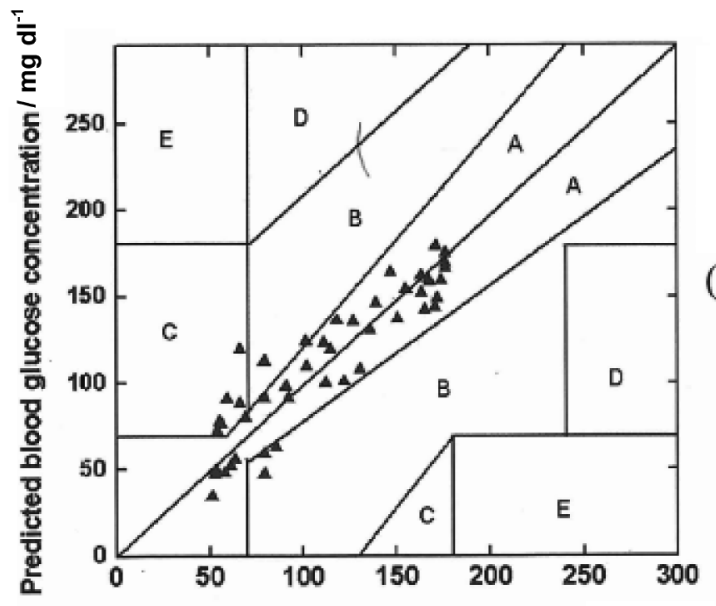

Actual blood glucose concentration / $\mathrm{mg} \mathrm{dl}^{-1}$

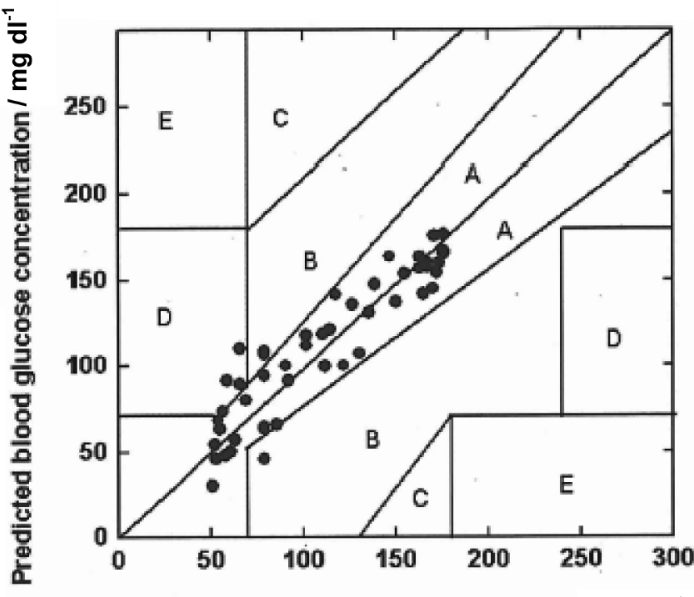

Actual blood glucose concentration $/ \mathrm{mg} \mathrm{dl}^{-1}$

(c)

Fig. 21 EGA plots between the actual and predicted blood glucose concentrations for (a) the PLS model based on the whole region. (b) PLS model obtained by using the informative region of $1574-1736 \mathrm{~nm}$ suggested by MWPLSR. (c) PLS model developed by use of the optimized informative region of $1616-1733 \mathrm{~nm}$ obtained by SCMWPLS. Reproduced from Ref. 79 with the permission. Copyright (2006) Elsevier.

information about blood glucose, and less interference than others. ${ }^{79}$

Figures 21(a), 21(b) and 21(c) show EGA plots for the three PLS models developed by using the whole region, the region of 
$1574-1736 \mathrm{~nm}$ suggested by MWPLSR, and the optimized region of $1616-1733 \mathrm{~nm}$ yielded by SCMWPLS. ${ }^{79}$ All of the EGA plots show that the mainstream of the prediction values is located within zone A, which is defined as the clinically correction. These EGA plots confirm that the prediction results for the noninvasive blood glucose measurements by NIR spectroscopy are clinically acceptable. However, the EGA plots for those three models are significantly different from each other in terms of the numbers and positions of points in each zone. It was found that $85.5,80.2$, and $83.3 \%$ of the predicted blood glucose concentrations fall in zone A for the models obtained with SCMWPLS, MWPLSR and the whole region, respectively. Further, 7.2, 9.4, and $8.3 \%$ of the predicted values are found in zone B, and their $7.3,10.4$, and $8.4 \%$ are seen in zone D for these three models. The EGA results clearly reveal that the PLS model obtained by using the optimized region selected by SCMWPLS provides not only the best performance in statistical point, but also presents the best clinical accuracy among the three models. ${ }^{79}$

\subsection{Applications of NIR imaging}

It was only last decade that NIR imaging was developed significantly. ${ }^{80,81}$ NIR imaging collects data in a spatially resolved manner, so that one can learn from where on a sample a NIR spectrum is obtained. Therefore, novel information about the special distribution of sample components can be derived. Chemical imaging data, not only NIR imaging data, but also others, can be represented as a three-dimensional cube spanning one wavelength and two special dimensions. This data construct is called a hyper cubic. To handle these hyper cubes, one uses a variety of chemometrics methods, such as PCA.

NIR imaging has been extensively applied to studies in biomedical, pharmaceutical, food, and polymer fields. In this section, a temperature-dependent NIR imaging study is introduced of diffusion process of butanol (OD) into polyamide $11 .^{80,81}$

4.5.1 Temperature-dependent NIR imaging study of the diffusion process of butanol (OD) into polyamide 11

Time-resolved NIR imaging was applied to the diffusion process of butanol (OD) into polyamide 11 (PA11) to demonstrate any significant differences of the diffusion rate below and above the glass transition temperature of PA11. ${ }^{82}$ This study allowed us to monitor the diffusion front by the intensity decrease of a $\mathrm{NH}$-specific absorption band of PA11 due to the NH/ND isotope exchange.

NIR imaging in the transmission mode is a unique to visualize local chemical differences, and thus offers the possibility of combining spectral and spatial information. Unger et al. ${ }^{82}$ used the diffusant butanol (OD) instead of $\mathrm{D}_{2} \mathrm{O}$, because it allows monitoring of the diffusion in an experimentally manageable time frame. The mobile NH protons of PA11 undergo H/D exchange with the diffusant butanol (OD), and since this isotope exchange is directly linked to the diffusion of butanol (OD) into PA11, the NIR imaging technique can be applied to monitor the diffusion process as a function of time, and to follow the lateral extension of the diffusion front.

Figure 22 shows NIR spectra in the $5050-4750 \mathrm{~cm}^{-1}$ region of PA11 film before and after deuteration for $5 \mathrm{~h} 35 \mathrm{~min}$ at $50^{\circ} \mathrm{C} .{ }^{82}$ It can be seen from Fig. 22 that the intensity decrease in the $4965 \mathrm{~cm}^{-1}$ band due to the combination of $v(\mathrm{NH})+$ amide I is much less than that in the $4875 \mathrm{~cm}^{-1}$ band arising from the combination of $v(\mathrm{NH})+$ amide II. This happens because the $4965 \mathrm{~cm}^{-1}$ band is increasingly superimposed by the evolving $2 \times v(\mathrm{ND})$ overtone with progressing deuteration. Thus, to follow the deuteration progress with time, Unger et al. ${ }^{82}$ used

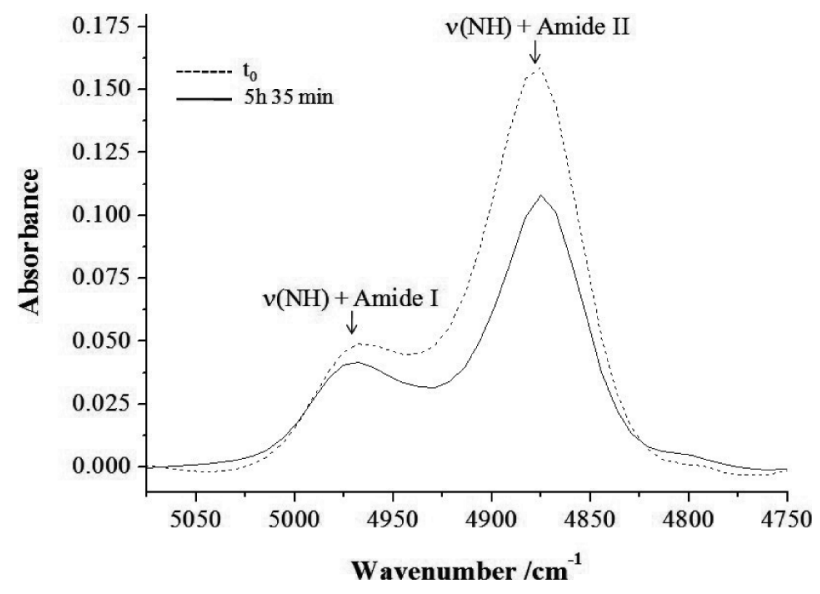

Fig. 22 FT-NIR imaging spectra of PA 11 before (- - -) and after $5 \mathrm{~h}$ 35 min (-) deuteration with butanol (OD) at $50^{\circ} \mathrm{C}$. Reproduced from Ref. 82 with the permission. Copyright (2011) Society for Applied Spectroscopy.

the band at $4875 \mathrm{~cm}^{-1}$. In order to develop NIR contour plots, the $v(\mathrm{NH})+$ amide II band was integrated in the $4935-4800 \mathrm{~cm}^{-1}$ region with a baseline from 5030 to $4800 \mathrm{~cm}^{-1}$. Moreover, a consistent color code was applied to the NIR images for investigations at different temperatures. Thus, the color assignment is based on the minimum and maximum absorbance values of the initial image at $t_{0}$.

Figure 23 displays NIR images based on the integrated $v(\mathrm{NH})+$ amide II band for (A) the deuteration times $t_{0}$ and (B) $10 \mathrm{~h} 15 \mathrm{~min}$ at $25^{\circ} \mathrm{C}$ and (C) $t_{0}$ and (D) $1 \mathrm{~h} 45 \mathrm{~min}$ at $50^{\circ} \mathrm{C} .{ }^{82}$ On the left side (blue) the butanol (OD) and on the right side (light pink) the PA11 film are mapped. No butanol (OD) had diffused into the polymer film at the starting $(t=0 \mathrm{~min})$. Thus, the PA11 part of the image is homogeneously lightly pink colored. After $10 \mathrm{~h} 15 \mathrm{~min}$ at $25^{\circ} \mathrm{C}$ the deuteration front had moved into the PA11 area, and the $v(\mathrm{NH})+$ amide II band decreased with the NH/ND exchange to a yellow color (Fig. 23(B)). It is of note that, in contrast to the deuteration progress at $25^{\circ} \mathrm{C}$, the front of the $\mathrm{NH} / \mathrm{ND}$ exchange at $50^{\circ} \mathrm{C}$ had already reached approximately the same position at about $1 \mathrm{~h}$ 45 min (Fig. 23(D)). It can be seen from Fig. 23 that below and above the glass transition temperature of PA11 significant differences in the diffusion rate occur.

Unger et al. ${ }^{82}$ investigated the type of diffusion from the NIR imaging data following the logarithmic form of

$$
\log d=\log A+a \log t
$$

The above equation allows the determination of the diffusion exponent, $a$, from the slope of a plot of $\log d$ ( $d$ measured in $\mu \mathrm{m})$ versus $\log t$ ( $t$ measured in $\mathrm{s})$. The diffusion front was evaluated by extracting spectra of pixels in eight neighboring rows extending perpendicular to the PA11/butanol (OD) borderline into the PA11 (Fig. 23(A), grey-shaded rectangle). Figures 24(A) and 24(B) illustrate determination of the diffusion front position for $25^{\circ} \mathrm{C}$ at (A) $t_{0}$ and (B) $10 \mathrm{~h} 15 \mathrm{~min} .{ }^{82}$ Figures 25(A) and 25(B) plot $\log d(d$, distance in $\mu \mathrm{m}$ of the butanol (OD) diffusion front from the borderline PA11/butanol (OD) versus $\log t$ ( $t$, deuteration time in $\mathrm{s}$ ) for the experiment at (A) $25^{\circ} \mathrm{C}$ and (B) $50^{\circ} \mathrm{C} .{ }^{82}$

In order to extract more information about the significant difference of the diffusion rate below $\left(25^{\circ} \mathrm{C}\right)$ and above $\left(50^{\circ} \mathrm{C}\right)$ 

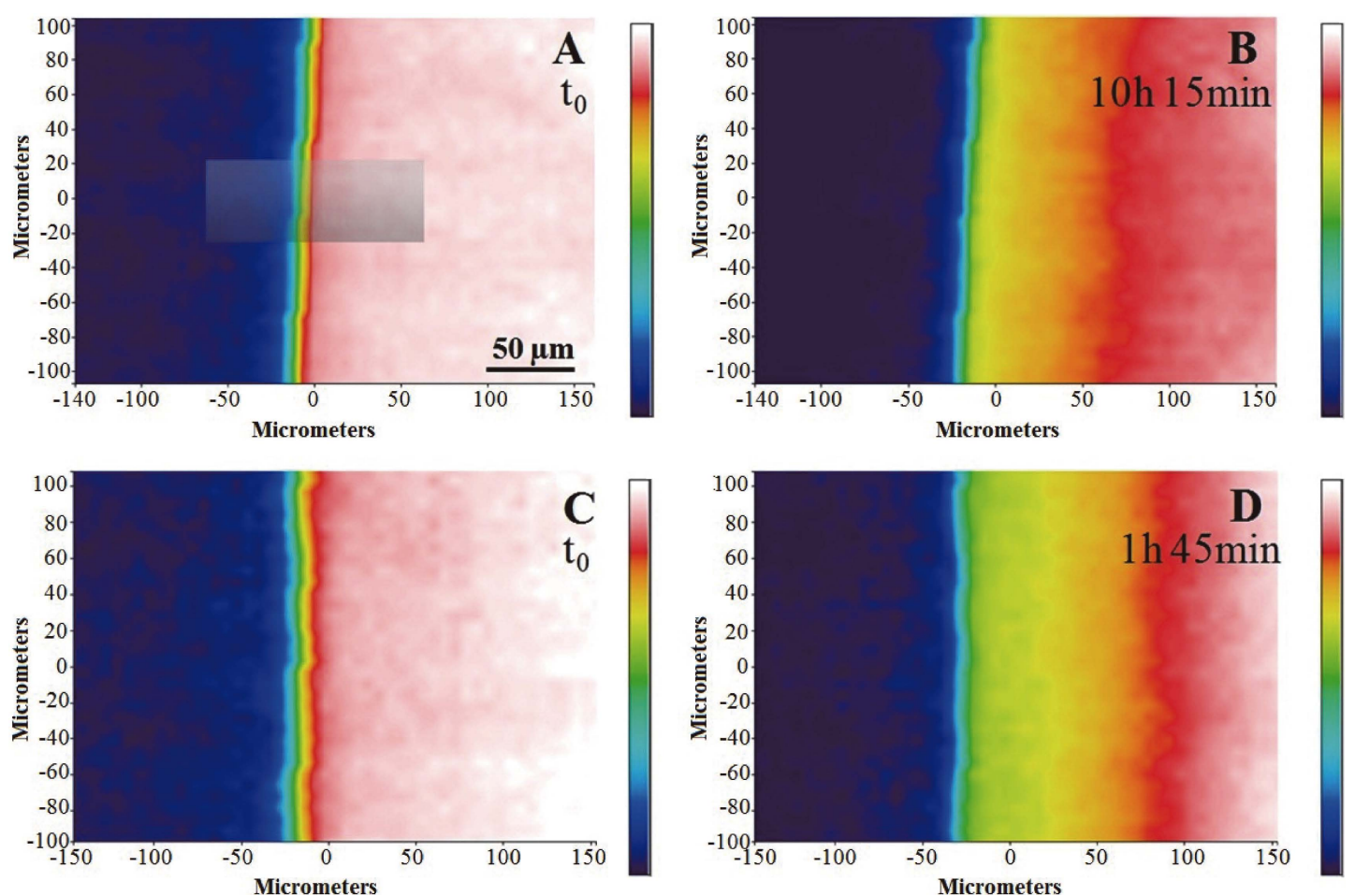

Fig. 23 FT-NIR images based on the integrated $v(\mathrm{NH})+$ amide II absorbance for (A) the deuteration times $t_{0}$ and (B) $10 \mathrm{~h} 15 \mathrm{~min}$ at $25^{\circ} \mathrm{C}$, (C) $t_{0}$ and (D) $1 \mathrm{~h} 45 \mathrm{~min}$ at $50^{\circ} \mathrm{C}$. Reproduced from Ref. 82 with the permission. Copyright (2011) Society for Applied Spectroscopy.
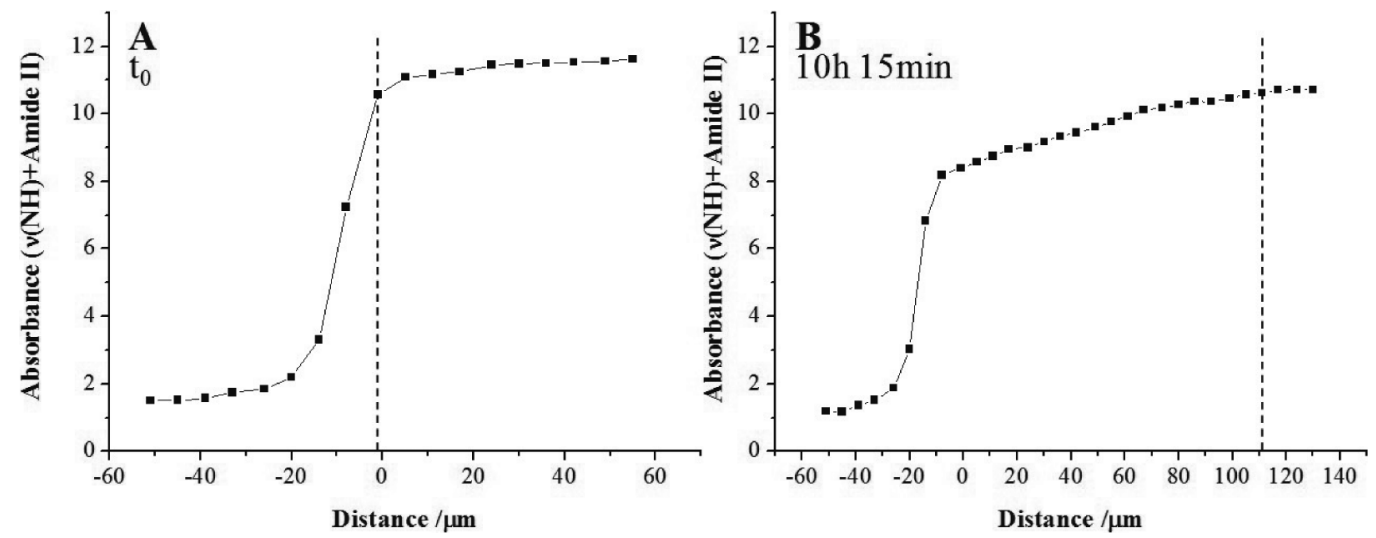

Fig. 24 Determination of the diffusion front position for the $25^{\circ} \mathrm{C}$ experiment at (A) $t_{0}$, (B) $10 \mathrm{~h}$ 15 min. The dashed lines indicate (A) the initial butanol (OD)/PA11 interface, (B) diffusion front. Reproduced from Ref. 82 with the permission. Copyright (2011) Society for Applied Spectroscopy.

the glass transition temperature of PA11, and notwithstanding the different diffusion types, Unger et al. ${ }^{82}$ calculated the diffusion coefficients based on Fickian diffusion according to a procedure that Rafferty and Koenig ${ }^{83}$ applied for imaging measurements. They also determined the type of diffusion at 25 and $50^{\circ} \mathrm{C}$. A case-II diffusion type was found for $25^{\circ} \mathrm{C}$, whereas at $50^{\circ} \mathrm{C}$ a Fickian-type diffusion was observed. Based on the assumption that the diffusion of the butanol (OD) and the NH/ND exchange occur simultaneously, diffusion coefficients of $1.00 \times 10^{-9}$ and $2.92 \times 10^{-9} \mathrm{~cm}^{2} / \mathrm{s}$ were derived for the experiments at 25 and $50^{\circ} \mathrm{C}$, respectively. ${ }^{82}$

\section{Future Prospects}

As described in this review, NIR spectroscopy is a powerful analytical tool from the standpoints of both basic science and applications. It is electronic spectroscopy as well as vibrational spectroscopy. In region $\mathrm{I}$, it is often used as electronic spectroscopy, while in other regions it is usually vibrational spectroscopy. To understand the versatility and diversity of NIR spectroscopy is very important for its application.

NIR spectroscopy should develop further strongly. Progress of NIR spectroscopy is expected in many aspects. In its basic studies, the intensities of overtones and anharmonicities and 

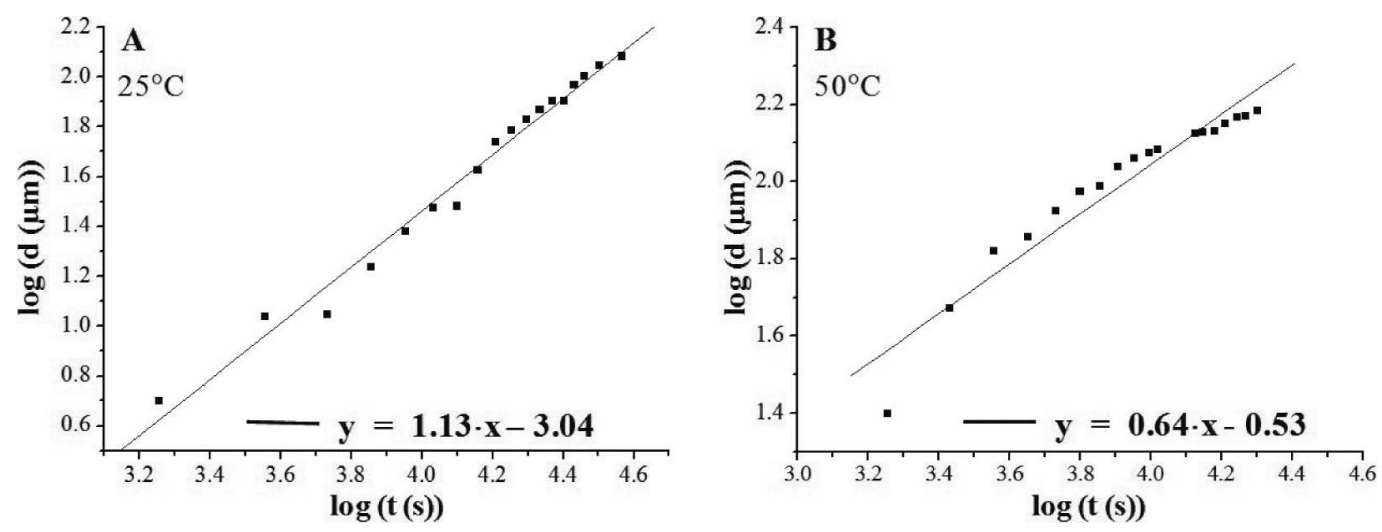

Fig. 25 Plots of $\log d$ ( $d$, distance in $\mu \mathrm{m}$ of the butanol (OD) diffusion front from the borderline PA11/butanol (OD)) versus $\log t\left(t\right.$, deuteration time in s) for the experiments at (A) $25^{\circ} \mathrm{C}$ and (B) $50^{\circ} \mathrm{C}$. Reproduced from Ref. 82 with the permission. Copyright (2011) Society for Applied Spectroscopy.

their relations to molecular interactions, such as hydrogen bonding, should be investigated more. Recently, we reported one good example of such studies. ${ }^{84}$ One good thing is rapid progress of quantum chemical calculations of overtones. ${ }^{26-28} \mathrm{We}$ suppose that quantum chemical calculations play very important roles in spectral analysis and investigations in NIR spectroscopy.

Recent advances in NIR instruments are of particular note. Those in NIR imaging systems, and PAT systems are very rapid and attractive. Applications of NIR imaging, including those that use portable instruments, should become popular. One can use NIR imaging for structural studies, chemical and physical characterizations, quality assessment, to growing monitoring in a field. Portable NIR spectrometers and hand-held spectrometers are already used in various places, including factories and fields. The miniaturization of portable spectrometers is still in progress, so that the working places of portable NIR spectrometers and hand-held spectrometers should become wider and wider. Progress in light sources, spectrometers, and detectors is also remarkable.

In conclusion, NIR spectroscopy should develop its versatility in wider areas of analytical chemistry.

\section{References}

1. H. W. Siesler, Y. Ozaki, S. Kawata, and H. M. Heise (ed.), "Near-Infrared Spectroscopy", 2002, Wiley-VCH, Weinheim.

2. Y. Ozaki, W. F. McClure, and A. A. Christy (ed.), "Near Infrared Spectroscopy in Food Science and Technology", 2006, Wiley Interscience, New York.

3. J. Workman and L. Weyer, "Practical Guide to Interpretive Near Infrared Spectroscopy", 2007, CRC Press, Boca Raton.

4. J. Workman and L. Weyer, "Practical Guide and Spectral Atlas for Interpretive Near-Infrared Spectroscopy, Second Edition", 2012, CRC Press, Boca Raton.

5. E. W. Ciurczak and J. K. Drennen III, "Pharmaceutical and Medical Applications of Near-Infrared Spectroscopy", 2002, CRC Press, Boca Raton.

6. C. A. Roberts, "Near-infrared Spectroscopy in Agriculture", 2004, American Society of Agronomy.

7. P. C. Williams, "Near-infrared Spectroscopy", 1996, NIR Publications, Chichester, UK.

8. K. Tichauer, "Near-Infrared Spectroscopy: Diagnosis of
Neonatal Hypoxia-Ischemia", 2010, VDM Verlag.

9. D. A. Burns and E. W. Ciurczak (ed.), "Handbook of NearInfrared Spectroscopy", 3rd ed., 2008, CRC Press, Boca Raton.

10. B. G. Osborne and T. Fearn, "Near Infrared Spectroscopy in Food Analysis", 1986, Longman Higher Education.

11. B. N. Figgis, "Introdution to Lifand Fields", 1966, Krieger Pub. Co.

12. A. Villringer and U. Dirangl (ed.), "Optical Imaging of Brain Function and Metabolism 2", 1997, Springer, Berlin.

13. E. W. Ciurczak, in "Handbook of Near-Infrared Analysis", ed. D. A. Burns and E. W. Ciurczak, 3rd ed., 2008, CRC Press, Boca Raton, 647.

14. M. Llusar, A. Badeness, J. Calbo, M. A. Tena, and G. Monros, J. Eur. Ceram. Soc., 2001, 21, 1121.

15. R. A. Candeia, M. A. F. Souza, M. I. B. Bernardi, S. C. Maestelli, I. M. G. Santos, A. G. Souza, and E. Longo, Mater. Res. Bull., 2006, 41, 183.

16. H. Martens and T. Næs, "Multivariate Calibration", 1989, John Wiley \& Sons, Chichester.

17. B. G. M. Vandegiste, D. L. Massart, L. M. C. Buydens, S. de Jong, P. L. Lewi, and J. Smeyers-Verbeke, "Handbook of Chemometrics and Qualimetrics: Part B", 1998, Elsevier, Amsterdam.

18. H. Mark and J. Workman Jr., "Chemometrics in Spectroscopy", 2007, Elsevier, Amsterdam.

19. R. Kramer, "Chemometrics Techniques for Quantitative Analysis", 1998, CRC Press, Boca Raton.

20. K. Varmuza and P. Filzmoser, "Introduction to Multivariate Statistical Analysis in Chemometrics", 2009, CRC Press, Boca Raton.

21. J. R. Hart, K. H. Norris, and C. Golumbic, Cereal Chem., 1962, 39, 94

22. D. R. Massie and K. H. Norris, Trans. ASAE, 1965, 8, 598.

23. F. F. Jöbsis, Science, 1977, 198, 1264.

24. Y. Ozaki and I. Noda (ed.), "Two Dimensional Correlation Spectroscopy", 2000, American Institute of Physics, Melville, New York, AIP Conference Proceedings, 503.

25. I. Noda and Y. Ozaki, "Two Dimensional Correlation Spectroscopy-Applications in Vibrational and Optical Spectroscopy", 2004, John Wiley \& Sons, Ltd., England.

26. J. R. Lane and H. G. Kjaergaard, J. Phys. Chem., 2010, 132, 174304.

27. Y. Futami, Y. Ozaki, Y. Hamada, M. J. Wojcik, and Y. Ozaki, Chem. Phys. Lett., 2009, 482, 320. 
28. Y. Futami, Y. Ozaki, Y. Hamada, M. J. Wojcik, and Y. Ozaki, J. Phys. Chem. A, 2011, 115, 1194.

29. J. H. Jiang, R. J. Berry, H. W. Siesler, and Y. Ozaki, Anal. Chem., 2002, 74, 3555.

30. Y. P. Du, Y. Z. Liang, J. H. Jiang, R. J. Berry, and Y. Ozaki, Anal. Chim. Acta, 2004, 501, 183.

31. L. Xu and I. Schechter, Anal. Chem., 1996, 68, 2392.

32. C. H. Spiegenman, M. J. McShane, M. J. Goets, M. Motamedi, Q. L. Yue, and G. L. Cote, Anal. Chem., 1998, 70,35 .

33. J. H. Kalivas, N. Roberts, and J. M. Sutter, Anal. Chem., 1989, 61, 2024.

34. D. J. Rimbaud, B. Walczak, D. L. Massart, I. R. Last, and K. A. Prebble, Anal. Chim. Acta, 1995, 304, 185.

35. P. J. Brown, J. Chemom., 1992, 6, 151.

36. Y. Z. Liang, Y. L. Xie, and R. Q. Yu, Anal. Chim. Acta, 1989, $222,347$.

37. U. Horchner and J. H. Kalivas, Anal. Chim. Acta, 1995, 311,1 .

38. C. B. Lucasius and G. Kateman, Trends Anal. Chem., 1991, $10,254$.

39. L. Norgaard, A. Saudland, J. Wagner, J. P. Nielsen, L. Munck, and S. B. Engelsen, Appl. Spectrosc., 2000, 54, 413.

40. L. Munck, J. P. Nielsen, B. Moller, S. Jacobsen, I. Sondergaard, S. B. Engelsen, L. Norgaard, and R. Bro, Anal. Chim. Acta, 2001, 446, 171.

41. S. Kasemsumran, Y. P. Du, K. Maruo, and Y. Ozaki, Chemom. Intell. Lab. Syst., 2006, 82, 97.

42. H. Shinzawa, B. Li, T. Nakagawa, K. Maruo, and Y. Ozaki, Appl. Spectrosc., 2006, 60, 631.

43. S. Kasemsumran, Y. P. Du, K. Maruo, and Y. Ozaki, Anal. Chim. Acta, 2004, 526, 193.

44. S. Kasemsumran, Y. P. Du, K. Murayama, M. Huehne, and Y. Ozaki, Anal. Chim. Acta, 2004, 512, 223.

45. S. Kasemsumran, Y. P. Du, K. Murayama, M. Huehne, and Y. Ozaki, Analyst, 2003, 128, 1471.

46. Y. P. Du, Y. Z. Liang, S. Kasemsumran, K. Maruo, and Y. Ozaki, Anal. Sci., 2004, 20, 1339.

47. Y. Hu, J. Zhang, H. Sato, Y. Futami, I. Noda, and Y. Ozaki, Macromolecules, 2006, 39, 3841.

48. C. Bastioli, "Handbook of Biodegradable Polymers", 2005, Rapra Technology Ltd., UK.

49. M. Yokouchi, Y. Chatani, H. Tadokoro, K. Teranishi, and H. Tani, Polymer, 1973, 14, 267.

50. R. H. Marchessault and J. Kawada, Macromolecules, 2004, 37, 7418 .

51. Y. Doi, S. Kitamura, and H. Abe, Macromolecules, 1995, $28,4822$.

52. H. Sato, M. Nakamura, A. Padermshoke, H. Yamaguchi, H. Terauchi, S. Ekgasit, I. Noda, and Y. Ozaki, Macromolecules, 2004, 37, 3763.

53. H. Sato, K. Mori, M. Rumi, Y. Ando, I. Tagahashi, J. M. Zhang, H. Terauchi, F. Hirose, K. Senda, K. Tashiro, I. Noda, and Y. Ozaki, Macromolecules, 2006, 39, 1525.

54. H. Sato, R. Murakami, A. Padermshoke, F. Hirose, K. Senda, I. Noda, and Y. Ozaki, Macromolecules, 2004, 37, 7203.

55. J. M. Chalmers, "Spectroscopy in Process Analysis", 2000, CRC Press.

56. K. A. Lee, in "Near-Infrared Spectroscopy in Food Science and Technology", ed. Y. Ozaki, W. F. McClure, and A. A. Christy, 2006, Wiley Interscience, Hoboken, NJ, 361.
57. H. W. Siesler in "Near-Infrared Spectroscopy-Principle, Instruments, Applications", ed. H. W. Siesler, Y. Ozaki, S. Kawata, and H. M. Heise, 2002, Wiley-VCH, Weinheim, 247.

58. K. A. Bakeev, "Process Analytical Technology: Spectroscopic Tools and Implementation Strategies for the Chemical and Pharmaceutical Industries", 2010, Wiley.

59. M. Watari, H. Higashiyama, N. Mitsui, M. Tomo, and Y. Ozaki, Appl. Spectrosc., 2004, 58, 248.

60. M. Watari and Y. Ozaki, Appl. Spectrosc., 2004, 58, 1210.

61. M. Watari and Y. Ozaki, Appl. Spectrosc., 2005, 59, 600.

62. M. Watari and Y. Ozaki, Appl. Spectorosc., 2005, 59, 912.

63. Y. Morisawa, S. Nomura, K. Sanada, and Y. Ozaki, Appl. Spectrosc., 2012, 66, 665.

64. I. D. Belova, Y. E. Roginskaya, R. R. Shifrina, S. G. Gagarin, Y. V. Plekhanov, and Y. N. Venevtsev, Solid State Commun., 1983, 47, 577.

65. L. Stichauer, G. Gavoille, and Z. Simsa, J. Appl. Phys., 1996, 79, 3645.

66. N. Pailhé, A. Wattiaux, M. Gaudon, and A. Demourgues, $J$. Solid State Chem., 2008, 181, 1040.

67. H. M. Heise, in "Infrared and Raman Spectroscopy of Biological Materials", 2000, Marcel Dekker, New York, 259.

68. H. M. Heise, in "Near-Infrared Spectroscopy_Principles, Instruments, Applications", H. W. Siesler, Y. Ozaki, and S. Kawata, 2002, Wiley-VCH, Weinheim, 289.

69. Y. Tong, "Functional Study of the Brain and Peripheral Nerves Using Near-Infrared Spectroscopy", 2011, Proquest, Umi Dissertation Publishing.

70. Y. P. Du, S. Kasemsumran, J. Jiang, and Y. Ozaki, in "Handbook of Near-Infrared Analysis", 3rd ed., 2007, CRC Press, 1.

71. M. R. Robinson, R. P. Eaton, D. M. Haaland, G. W. Koepp, E. V. Thomas, B. R. Stallard, and P. L. Robinson, Clin. Chem., 1992, 38, 1618.

72. U. A. Muller, B. Mertes, C. Fischbacher, K. U. Jageman, and K. Danzer, Int. J. Artific. Org., 1997, 20, 285.

73. R. Marbach, T. H. Koschinsky, F. A. Gries, and H. M. Heise, Appl. Spectrosc., 1993, 47, 875.

74. R. Marbach and H. M. Heise, Appl. Optics, 1995, 34, 610.

75. H. M. Heise, R. Marbach, and A. Bittner, J. Near Infrared Spectrosc., 1998, 6, 361.

76. K. Maruo, M. Tsurugi, J. Chin, T. Ota, H. Arimoto, Y. Yamada, M. Tamura, M. Ishii, and Y. Ozaki, IEEE J. Sel. Top. Quantum Electron., 2003, 9, 322.

77. K. Maruo, M. Tsurugi, M. Tamura, and Y. Ozaki, Appl. Spectrosc., 2003, 57, 1236.

78. K. Maruo, T. Oota, M. Tsurugi, T. Nakagawa, H. Arimoto, M. Tamura, Y. Ozaki, and Y. Yamada, Appl. Spectrosc., 2006, 60, 441 .

79. S. Kasemsumran, Y. P. Du, K. Maruo, and Y. Ozaki, Chemom. Intell. Lab. Syst., 2006, 82, 97.

80. R. Salzer and H. W. Siesler, "Infrared and Raman Spectroscopic Imaging”, 2009, Wiley-VCH.

81. S. Sasic and Y. Ozaki, "Raman, Infrared, and Near-Infrared Chemical Imaging”, 2010, John Wiley \& Sons, Inc.

82. M. Unger, Y. Ozaki, and H. W. Siesler, Appl. Spectrosc., 2011, 65, 1051.

83. D. W. Rafferty and J. L. Koenig, J. Controlled Release, 2003, 83, 29.

84. T. Gonjo, Y. Futami, Y. Morisawa, M. J. Wojcik, and Y. Ozaki, J. Phys. Chem. A, 2011, 115, 9845. 